This is the post-print version of the following article:

Corciolani, M., Gistri, G., Pace, S. (2019) "Legitimacy struggles in palm oil controversies: An institutional perspective", Journal of Cleaner Production, 212, March, 1117-1131, ISSN 0959-6526, DOI 10.1016/j.jclepro.2018.12.103 (Available online 11 December 2018).

The final publication is available at:

https://www.sciencedirect.com/science/article/abs/pii/S0959652618338125 


\title{
Legitimacy struggles in palm oil controversies: An institutional perspective
}

\author{
Matteo Corciolani ${ }^{\mathrm{a},}$, Giacomo Gistri $^{\mathrm{b}}$, Stefano Pace ${ }^{\mathrm{c}}$ \\ ${ }^{a}$ Department of Economics and Management, University of Pisa, Via Ridolfi 10 - 56124, Pisa (Italy) \\ ${ }^{\mathrm{b}}$ Department of Political Sciences, Communication and International Relations, University of Macerata, Via Don \\ Minzoni, 22a - 62100 Macerata (Italy) \\ ${ }^{\mathrm{c}}$ Kedge Business School, Rue Antoine Bourdelle, Domaine de Luminy BP 921, 13288 Marseille Cedex 9 (France) \\ * Corresponding author. \\ E-mail address: matteo.corciolani@unipi.it (M. Corciolani).
}




\title{
Legitimacy struggles in palm oil controversies: An institutional perspective
}

\begin{abstract}
Palm oil is an ingredient largely used in the food, energy and cosmetics industries. However, it is subject to controversies related to its being considered unhealthy and responsible for deforestation, greenhouse gas emissions and human rights abuses. Yet, palm oil is a rare topic of discussion in the literature on legitimacy struggles. Based on an automated content analysis of 3,713 global newspaper articles downloaded from LexisNexis covering the period 1979-2017, we longitudinally examined the evolution of palm oil discussions over time. With this method, we were able to focus on both the content and the styles of communication. We thus obtained critical insights about how often different themes are mentioned in discussions on the palm oil market (i.e. the economic, environmental, health and social impacts of palm oil) and how three specific linguistic strategies are implemented by the media (i.e. a focus on promotion vs. prevention motivations, the adoption of analytic vs. narrative writing styles and references to specific vs. general stakeholders). In this way, we could better understand how different types of legitimacy have been emerging over time and in which geographic areas they have been most significant. In general, we show that pragmatic legitimacy is losing importance in favour of moral legitimacy and, more specifically, that pragmatic legitimacy remains the key for palm oil-producing countries, while moral legitimacy is more significant for palm oil-consuming countries. This study thus serves as a starting point for research on palm oil legitimacy struggles. Additionally, it offers useful insights for practitioners, policy makers and researchers in evaluating the status of the palm oil debate.
\end{abstract}

Keywords: palm oil; legitimacy struggles; pragmatic legitimacy; moral legitimacy; linguistic strategies; automated content analysis. 


\section{Legitimacy struggles in palm oil controversies: An institutional perspective}

Funding: This research did not receive a grant from funding agencies in the public, commercial, or not-for-profit sectors.

Word count: 13,988 words

\section{Introduction}

Palm oil (PO) is a product widely used in the food, energy and cosmetics industries. In fact, its high fat content and diverse range of uses combined with a low market price make PO and its co-product palm kernel oil particularly appealing (Hansen et al., 2015). Notably, while only 7\% of the world's agricultural land is dedicated to the cultivation of oil palms, this land provides almost $40 \%$ of the global vegetable oil production (Rival and Levang, 2014). Oosterveer (2015) reports that approximately half of the products in a typical supermarket contain PO. Hansen et al. (2015, p. 140) maintain that PO is now 'the most produced and consumed vegetable oil in the world', and Choong and McKay (2014) predict that the total world consumption of PO will be approximately 43 million tons in 2020. However, PO is also subject to relevant controversies (e.g. Disdier et al., 2013; Oosterveer, 2015). For instance, because PO contains saturated fats, its high consumption has been related to obesity and cardiovascular diseases (Chong and Ng, 1991; McNamara, 2010) and, more recently, even to cancer (Chapman, 2017). Due to the rapid expansion of massive oil palm plantations, PO has then been associated with deforestation, damage to biodiversity and an increase of carbon released into the atmosphere (Reijnders and Huijbregts, 2008; Saswattecha et al., 2017). Additionally, PO production has been linked to violations of property rights, child labour and other human rights abuses (D’Antone and Spencer, 2014, 2015).

The emergence of these controversies, which have jeopardised the legitimacy of PO, has resulted in a call for a different approach to its production, as illustrated by a growing interest in a more sustainable type of PO (Boons and Mendoza, 2010; Hansen et al., 2015). One of the most 
important activities in this sense has been the creation of the non-profit association Roundtable of Sustainable Palm Oil (RSPO), launched in 2004 due to a multi-stakeholder initiative involving the World Wildlife Fund for Nature (WWF), Unilever, Migros, Aarhus United Ltd., Karlshamns and the Malaysian Palm Oil Association (MPOA). The RSPO's main objective is to promote 'the growth and use of sustainable palm oil through co-operation within the supply chain and open dialogue with its stakeholders' (RSPO, 2004). By setting the standard for the production of sustainable PO and creating a system of certification (e.g. by developing the Green Palm Certificates and RSPO Trademark; D'Antone and Spencer, 2014), the RSPO should help reduce the social and environmental problems associated with PO (Von Geibler, 2013). However, the RSPO is not without criticism. For instance, while the RSPO has tried to make the global production of PO more sustainable, it has been accused of adopting too lenient an approach in addressing the related environmental and social issues. Consequently, another sustainable PO initiative emerged in 2013 called the Palm Oil Innovation Group (POIG) (D’Antone and Spencer, 2014). However, these alternatives are not deemed able to completely address the concerns relating to the use of $\mathrm{PO}$, as indicated by the spread of boycotts and the development of a PO-free market (Disdier et al., 2013).

Although we have witnessed a growing number of articles about PO, these contributions have mainly looked at the technical aspects of how to manage, treat and use the large quantity of residue and waste produced by the PO industry (Hansen et al., 2015). Conversely, the legitimacy struggles characterising this product have been largely ignored in the literature. In an attempt to help fill this gap, we took an institutional approach and tried to better address the evolution of the legitimacy struggles occurring in this domain. Legitimacy struggles, in particular, may be conceptualised as discursive processes aimed at legitimating, delegitimating or relegitimating an object over time (e.g. Joutsenvirta and Vaara, 2015; Vaara et al., 2006). We specifically aim to empirically investigate how these legitimacy struggles are developing within the context of the PO market and to better understand what they tell us more generally about PO legitimation. We 
believe such a study could also be helpful for practitioners and policy makers, who may obtain interesting insights about how to operate in this contested market and, more significantly, about how to develop demand for sustainable PO.

With this main objective in mind, we analysed 3,713 articles on PO that were published in leading international newspapers during the period 1979-2017. By performing an automated content analysis of this material (Humphreys and Wang, 2018), we focused on both the content and the style of communication used. We thus obtained critical insights about how often different themes are mentioned in this field and how the media implements specific linguistic strategies in their coverage. In this way, we tried to better understand how different types of legitimacy have emerged over time and in which geographic areas they have become more significant. The reminder of this article is organised as follows. In section 2, we introduce our theoretical background. In section 3, we present our research objectives, and in section 4 we discuss the materials and methods. In section 5, we present the results, followed by the discussion and implications in section 6 . Section 7 concludes with a discussion of the study limitations and suggestions for future research.

\section{Theoretical background}

\subsection{Palm oil literature and institutional perspectives}

Although we cannot delve into a detailed investigation of $\mathrm{PO}$ research in this article (for a recent review, see Hansen et al., 2015), it is important to summarise two fundamental results of our review. First, we found that research on PO has increased exponentially in recent years. For instance, searching the expression 'palm oil' on SCOPUS (accessed February 16, 2018) revealed that the related number of journal articles had increased from 340 in 2009 to 989 in 2017. Second, we discovered that the majority of the 9,245 articles returned address agricultural and biological sciences, chemistry and chemical engineering, while only a small number were related to social sciences $(3.33 \%$ of the total) or business, management and accounting $(2.51 \%)$. We therefore 
agree with Hansen et al. (2015) that more studies about non-residue topics, such as biodiversity and economic, social and environmental issues, could be particularly useful in analysing alternative aspects of PO production and consumption.

Indeed, while research on residue has mainly concentrated on the "technical feasibility of technologies or the characteristics of the products produced from the residues' (Hansen et al., 2015 , p. 144), the research on non-residue topics has increasingly clarified equally relevant topics related to PO. For instance, Boons and Mendoza (2010) analysed how actors involved in the production and consumption of biofuels (such as PO) conceptualise sustainability differently. Sustainability is also a key construct for Choong and McKay (2014), who examined how the Malaysian PO industry is trying to deliver sustainable PO products, and for D'Antone and Spencer (2014), who considered the development of the sustainable PO market as an example of marketisation. Von Geibler (2013) illustrated the effectiveness of setting standards in the case of PO and explored the strengths and weaknesses of the RSPO in detail. Oosterveer $(2015$, p. 146) examined the 'shifting power relationships in emerging governance arrangements addressing sustainability challenges in palm oil supply'. Saswattecha et al. (2017) explored how the environmental sustainability of Thai PO production can be improved in the future, and Jamaludin et al. (2018) developed a Palm Oil Mill Sustainability Index.

On the demand side, Disdier et al. (2013) demonstrated that negative information about PO products could influence consumers' willingness to pay, while Corciolani et al. (2016) examined the most salient topics PO is associated with by consumers on different social media platforms. More recently, Gassler and Spiller (2018) have studied mass balance (MB) chains in which certified and non-certified PO are mixed together. In carrying out a choice experiment about chocolate bars, they illustrated how the majority of consumers favour MB products over unlabelled alternatives, which implies that they prefer at least a guaranteed minimum of certified sustainable PO. 
Although this brief review is far from exhaustive, it shows that Hansen et al.'s (2015) call for new research on non-residue topics is being addressed by more scholars. However, to the best of our knowledge, no previous study has adopted an institutional perspective to explore the legitimacy struggles occurring at an international level in the PO market. We have therefore analysed this domain, taking inspiration from previous institutional work. We argue that this can be a relevant contribution to the literature on PO for at least two reasons. First, we believe that, as demonstrated in similar studies, institutional perspectives may significantly help in reconstructing multi-level processes of change and in facilitating exploration of the relationships between production and consumption practices (Vergragt et al., 2016). We believe this approach may be especially informative for our study, as we examined a contested market in which legitimation struggles are occurring. That is, we observed a context in which discrepancies emerged between organisations and society, which resulted in a contested market and a sort of 'legitimacy gap' (Sethi, 1979, cited in Montecchia et al., 2016). As summarised above, objections to PO may be particularly due to the fact that this ingredient is considered potentially harmful to human health, the natural environment and local communities (Oosterveer, 2015). As shown by Maguire and Hardy (2009) in their study of DDT deinstitutionalisation, adopting an institutional view may therefore be particularly helpful in investigating how the related processes of legitimation and delegitimation are developing. In detail, we deem it important to examine the frames most frequently associated with PO in this debate and the linguistic strategies used to communicate them, as well as how this discussion has evolved in different periods and geographic areas.

Second, we believe that, because such a study may increase our understanding of the dynamics of the PO market, it could also be helpful for practitioners and policy makers. That is, by showing how the meaning of PO production and consumption has changed over time and is differently defined in various geographic areas, we can provide key actors with significant insights about how to better organise their communication about PO. For instance, the results of our analysis may suggest to them how to alternatively frame the meaning of sustainable PO in terms 
of economic, environmental or social dimensions in different geographic areas (e.g. producing vs. consuming countries), which might pay different degrees of attention to these issues.

Because we mainly focus on how legitimacy struggles have developed in the context of PO, we think it important to introduce a few concepts from institutional theory that may better inform our results and discussion.

\subsection{Legitimacy theory and legitimacy struggles}

As explained above, one key construct in our research is legitimacy. In particular, we built our framework based on Suchman's (1995) work, which defines legitimacy as a 'generalised perception or assumption that the actions of an entity are desirable, proper or appropriate within some socially constructed system of norms, values, beliefs and definitions' (p. 574). Notably, the literature has increasingly acknowledged that firms' performances are significantly related to their ability to adapt to the established rules, norms and belief systems of the contexts in which they operate (e.g. Scott, 2001). Accordingly, legitimacy is now considered fundamental to help companies achieve their goals (Deephouse et al., 2017) and has become a central construct in several social science fields (for a recent review, see Suddaby et al., 2016).

One key issue that emerges in this literature is that legitimacy is not fixed over time. Rather, legitimacy is conceptualised in a dynamic way (Johnson et al., 2006). In other words, it is usually related to legitimation, which is the process through which legitimacy meanings change over years as long as organisations, sources, and criteria also evolve historically (Deephouse et al., 2017). As noted by Hoffman (1999), in fact, even legitimated organisational fields may be subject to criticism and institutional wars, which tend to undermine them and transform the attitudes and behaviours of their actors. Accordingly, legitimacy-based studies that are interested in a particular object (in our case, PO) generally aim at studying the broader social, economic or political factors that may influence its meanings and transformations over time (Mahadeo et al., 2011). This often means examining the development of legitimacy struggles about an issue, which, as we anticipated above, are the discursive processes implemented and aimed at legitimating, 
delegitimating, and relegitimating that object in specific social arenas (Joutsenvirta and Vaara, 2015; Maguire and Hardy, 2009; Vaara et al., 2006). In this regard, many authors also notice that linguistic strategies employed by the media are a fundamental aspect of the social construction of legitimacy (Suddaby and Greenwood, 2005; Vaara and Tienari, 2008). Luyckx and Janssens (2016, p. 1595), indeed, argued that legitimacy is especially 'shaped through linguistic resources'. Therefore, as maintained by Joutsenvirta and Vaara (2015) and others, the micro-level textual processes within legitimacy struggles to support the evolution of different discourses deserve more attention.

As long as legitimacy struggles develop, by paying more attention to these strategies it is possible to better identify how alternative discourses and types of legitimacy emerge in the same context (e.g. Humphreys, 2010). In this regard, two types of legitimacy that are often investigated in empirical settings are pragmatic legitimacy and moral legitimacy (e.g. Mahadeo et al., 2011). Suchman (1995) has defined pragmatic legitimacy as being based on 'self-interested calculations of an organisation's most immediate audience' (p. 578). Conversely, moral legitimacy does not rely on 'judgements about whether a given activity benefits the evaluator, but rather on judgements about whether the activity is "the right thing to do"" (Suchman, 1995, p. 579). We particularly refer to these types of legitimacy because they are deemed especially important in current perspectives on management (e.g. Scherer and Palazzo, 2011) and also seem to play a role in relation to PO. In the next section, we better link these ideas to the PO market and present our research objectives.

\section{Research objectives}

We examined the PO market with the general aim of illustrating how legitimacy struggles are developing in this context. Therefore, as several authors have suggested doing in this type of analysis (e.g. Vaara et al., 2006), we first identified the various concepts PO is associated with in the media. For instance, according to Oosterveer (2015) discussions about PO tend to refer to its 
potentialities in terms of economic progress and to fears related to the 'environmental and social consequences of its production, processing, and trade' (p. 146). According to other authors, PO is also related to health concerns on the part of consumers (Chong and Ng, 1991; Disdier et al., 2013). We therefore expected to find economic, environmental, health and social themes to be particularly salient in our data as well.

Once we identified the main frames usually associated with PO, our second objective became to understand the linguistic strategies through which these topics are communicated in international newspapers. We focused on three distinct strategies concerning the specific motivations expressed, the writing styles used and the stakeholders mentioned by journalists in their articles. Building on regulatory focus theory (Higgins, 1997), we supposed that, when the media's discussions about PO tended to highlight rewards or gains instead of risks or losses, the media's main motivation was to promote positive outcomes instead of prevent negative issues relating to PO. Similarly, we hypothesised that, instead of using a narrative writing style, a more analytical writing style could be used to describe issues that are more technical than descriptive (Tausczik and Pennebaker, 2010). Furthermore, by analysing whether the discussion was related to specific actors (e.g. consumers, manufacturers, retailers) or more in general to public interest, we had a better idea of the potential target of the various considerations regarding PO. Then, taking all these results together and applying Suchman (1995)'s definition, we could identify the types of legitimacy that are emerging in this context. Indeed, as other authors have noted in similar research (Joutsenvirta, 2011; Vaara and Tienari, 2008; Vaara et al., 2006), themes conveyed by the media tend to reflect more complex ideological assumptions that, sometimes unconsciously, are communicated by journalists to their audiences. Yet, to recognise the main discourses related to the themes identified in the data, it becomes fundamental to also detect the linguistic strategies used by writers in association with the topics of interest.

Thereafter, our third objective was to investigate how the various topics associated with PO and the interrelated types of legitimacy (e.g. pragmatic vs. moral) have evolved over time and how 
important they have become in different geographic areas. Specifically, regarding the longitudinal analysis, we divided the collected articles into four periods and analysed how the discussions changed over time. Finally, taking inspiration from Boons and Mendoza (2010), we distinguished between countries in which PO is (also) produced and countries in which PO is (only) consumed. We thus tested whether, compared to countries more interested in PO production, consuming countries paid significantly different attention to the aspects relating to PO that we identified above. The research methodology is introduced in the next section, followed by an explanation of the most important results.

\section{Materials and methods}

\subsection{Data collection}

We built our sample in June 2017 by downloading from the global LexisNexis database all the newspaper articles that mentioned the expression 'palm oil'. We used the LexisNexis 'all news' source, which only includes major world publications that are originally written in English, as we thought that newspapers with a large circulation and a focus on international news (such as the Guardian, the New Straits Times and the New York Times) could give us a better representation of global public opinion about PO (Humphreys, 2010; Joutsenvirta and Vaara, 2015; Vaara et al., 2006). Thus, rather than focusing on specific newspapers or geographic areas, we performed a 'keyword search' (Tamul and Martínez-Carrillo, 2017) to collect all the data that were potentially related to PO debates at an international level. More specifically, by selecting the LexisNexis 'at least five times' query, we avoided focusing on articles that just cited 'palm oil' while actually addressing different subjects. This enabled us to create a database of 3,713 articles published from 1979-2017.

Notably, newspapers articles are traditionally used to analyse public opinion (Chiles, 2017; Gamson et al., 1992). In fact, as a vehicle for the collection of different viewpoints, such as those of cultural leaders, organisations or consumers, the media is generally considered an excellent 
source to understand the overall perceptions of a given argument (Deephouse, 1996; Meyer and Rowan, 1977). Additionally, analysing a broad sample of newspapers is deemed to be a good method to adequately represent the various perceptions of legitimacy in a specific field (Dowling and Pfeffer, 1975; Humphreys, 2010).

\section{[Please Insert Table 1 About Here]}

In our case, as shown in Table 1, we analysed articles that appeared in the main newspapers of different geographic areas (i.e. Africa, Asia, Europe, Latin America, the Middle East, North America and Oceania), although more than half were downloaded from Asian newspapers. Indeed, Indonesia and Malaysia (where almost $90 \%$ of the world's PO is produced) are the most important players in this field (Choong and McKay, 2014), and China, India and Indonesia are among the principal consumers of PO (D'Antone and Spencer, 2015). These articles were published across different decades, although the majority were written after $2000^{1}$. This means that increasing attention has been given to this topic in more recent years.

\subsection{Data analysis}

As is usually done in the literature (e.g. Humphreys, 2010), we first conducted a manual, qualitative analysis to identify the most common ways in which PO was conceptualised in the investigated domain. This preliminary analysis was done on a subsample of 350 articles (almost $10 \%$ of the total) that were randomly extracted from our sample and stratified based on their geographic area. This enabled us to identify four main themes regarding PO - the economic, environmental, health and social issues associated with its use. The first two authors independently coded each of these 350 articles by following a procedure of open, selective and theoretical coding (Glaser and Strauss, 1967). Inter-coder disagreements were then discussed with

\footnotetext{
${ }^{1}$ See Appendix A for a complete list of the news sources.
} 
the third author until a shared interpretation was obtained. At the end of this process, the two first authors had an average level of agreement of $93.28 \%$.

Next, we conducted a quantitative analysis of the downloaded material to more precisely measure the frequencies with which these themes appeared within our sample. To do this, we applied the method of Pennebaker et al. (2015), which consists of creating specific dictionaries of keywords to operationalise the theoretical categories. We performed this analysis using the software Linguistic Inquiry and Word Counting (LIWC), which is typically employed in this type of research (Humphreys and Ward, 2018). LIWC was particularly useful because it includes several pretested dictionaries (Pennebaker et al., 2015) that in our study were deemed appropriate to measure two topics of interest, the economic and health issues ${ }^{2}$. When LIWC did not provide us with any pre-tested dictionary to measure our variables, we created ad hoc dictionaries and pretested them following the method proposed by Pennebaker et al. (2007). We used this technique to investigate the environmental and social themes and to consider the main stakeholders (e.g. consumers, non-governmental organisations [NGOs], retailers) to whom the various themes were related in the analysed articles. For all these nine additional dictionaries, we again followed Pennebaker et al. (2007) by asking three external coders to evaluate whether to measure the proposed category (e.g. environmental issues) the keywords we proposed for these dictionaries (e.g. climate, deforestation, ecology) should be kept or removed. If at least two judges agreed on a single keyword, we kept it; otherwise, we removed it from the dictionary (see Table 2 for the complete list of dictionaries).

[Please Insert Table 2 About Here]

\footnotetext{
2 While we measured the 'health' variable using the 'health' dictionary available in LIWC, we measured the 'economic' dimension using the 'work' dictionary, which we deemed appropriate for considering production and trade details.
} 
We used these dictionaries to analyse the newspaper articles at both the article and word levels (see Humphreys, 2010 for a similar approach). First, we historically examined the emergence of the various themes to better interpret the evolution of PO themes over time. To run this analysis, we divided our articles into four periods of about 10 years each (i.e. 1979-1990; 1991-2000; 2001-2010; 2011-2017) ${ }^{3}$. Based on common practices in similar studies (e.g. Ertimur and Coskuner-Balli, 2015; Humphreys and Latour, 2013), we made this decision to reduce the potential noise in the data (e.g. occasional peaks) and to avoid potentially spurious effects due to the identification of longer periods. This choice is also consistent with the perspective adopted by Smith (1998), who explains that, although there are some limitations, the decade is often used in this type of analyses because it tends to possess distinctive cultural characteristics ${ }^{4}$. In this analysis, it was important to establish the main article topics (Matthes and Kohring, 2008); thus, we counted all articles on a specific theme (as 1 or 0 for each document) rather than identifying the exact number of words related to that theme in each article. Following the common practices in the literature (e.g. Humphreys, 2010), we decided that an article could be coded as being about one topic when it included a percentage of words related to the topic that was higher than the overall mean percentage of words related to it in other articles in the same group (i.e. for us, the same geographic area).

Second, we more deeply explored the linguistic strategies used by writers to communicate their ideas and the countries in which certain PO themes were discussed in more detail. In these cases, we performed an analysis by word in order to run some correlational analyses between our key themes and other dictionaries (Pennebaker et al., 2015) and some $t$-tests to compare POproducing countries and PO-consuming countries ${ }^{5}$. The findings of these analyses are described next.

\footnotetext{
${ }^{3}$ The 1979-1980 period has been included in the 1981-1990 decade because otherwise it referred to too few articles.

${ }^{4}$ Moreover, it is important to remark that the empirical investigation shown in Figure 1, which presents an additional analysis about shifts in themes year by year, provided the same pattern of results.

${ }^{5}$ The descriptive statistics for all the variables used in the analyses appear in Appendix B.
} 


\section{Results}

\subsection{Thematic analysis}

To examine the various topics PO was associated with in our period of analysis, we performed a thematic analysis (see Humphreys, 2010 or Vaara et al., 2006 for similar approaches). This analysis explored the most important changes in those themes that, according to our qualitative research, were used more often when discussing PO. Table 3 illustrates that the importance of the economic theme has changed over time. While from 1979-1990, more than $60 \%$ of all articles on PO were about economic issues, this percentage decreased to approximately $50 \%$ in the 1991-2000 period (a $t$-test revealed that the difference between these two periods is statistically significant at the $p<0.05$ level) and to almost $40 \%$ in the $2001-2010$ period (Percentage $_{1991-2000}>$ Percentage $\left._{2001-2010}, p<0.05\right)$. However, the attention to economic issues went back to being relevant in almost $50 \%$ of all articles in the $2011-2017$ period (Percentage $2001-$ $2010<$ Percentage $_{2011-2017}, p<0.05$ ). This can be explained by the major destruction of tropical forests in Indonesia and Papua New Guinea in 1997, which followed an important extension of oil palm plantations into tropical areas since the $1990 \mathrm{~s}$, and the increasing number of protests about the environmental and social impacts of PO production (Oosterveer, 2015). After 2000, therefore, the media started paying less attention to economic issues in favour of other emerging topics. After 2010, economic arguments were considered relevant again (see also Figure $1^{6}$ ) because the development of the PO market was directly linked to potentially positive impacts, such as poverty alleviation and the improvement of living standards in rural areas (Gillespie, 2012).

\section{[Please Insert Figure 1 About Here]}

\footnotetext{
${ }^{6}$ As clarified in the methodology section, in the alternative analysis illustrated in Figure 1, we calculated changes in percentages of words by year instead of counting all articles about each topic (see note 4).
} 
Conversely, Table 3 suggests that the relevance of the environmental theme has constantly increased over time. While from 1979-2000, less than 20\% of all articles on PO were about environmental issues, this percentage was more than $30 \%$ in the $2001-2010$ period (Percentage $_{1991-2000}<$ Percentage $_{2001-2010}, p<0.05$ ) and almost $40 \%$ in the $2010-2017$ period (Percentage $2001-2010<$ Percentage $_{2011-2017}, p<0.05$ ). To understand these changes, we highlight that the RSPO activity was launched in 2004. Moreover, a 2010 Greenpeace campaign called 'Ask Nestlé to give rainforests a break' was particularly successful on social media and made many consumers aware of the environmental impacts of PO (D'Antone and Spencer, 2015). Furthermore, in 2015, Ségolène Royal, France's Minister of Ecology, attacked Ferrero for using PO in Nutella and for contributing to the deforestation and destruction of habitats (Corciolani et al., 2016). Thus, many of the events that significantly affected the emergence of an environmental theme happened after 2000. However, the increasing importance of environmental issues has been less evident in Europe, where (as detailed below) the current debate has been predominantly based on health issues.

[Please Insert Table 3 About Here]

Table 3 also shows that attention to health issues has significantly decreased over time. While from 1979-2000, more than 50\% of all articles on PO were about health issues, from 20012017 less than $40 \%$ were related to health issues $\left(\right.$ Percentage $_{1991-2000}>$ Percentage $_{2001-2010}, p<$ 0.05). As illustrated by McNamara (2010), in fact, all tropical oils have been the target of a critical campaign (especially in the US) that started in the 1980s. It was said that PO consumption could increase blood cholesterol levels and lead to cardiovascular diseases (Chong and Ng, 1991). Therefore, in 1987, the US introduced specific legislation to discriminate against tropical oils by imposing special labelling restrictions on products containing them (Nordin et al., 2010). However, as typically happens in the context of food and nutrition, several other products then 
replaced the 'demon $d u$ jour', including simple sugars and high-fructose corn syrup (McNamara, 2010), thus decreasing the importance of PO. An interesting exception to this trend is the situation in Europe, where (as reported by the Guardian [Hucal, 2015]) recent attention was given to health issues related to PO consumption. Indeed, it is only since December 2014 that companies operating in Europe have been subject to a new regulatory requirement that forces them to indicate which vegetable oil they use in their products (Corciolani et al., 2016). This has made many stakeholders aware of the widespread use of PO, leading them to publish online lists of PO-free products or to launch public petitions to ask companies to stop using PO (D'Antone and Spencer, 2015).

Finally, Table 3 shows that the significance of the social theme has also significantly increased over the years. While from 1979-1990, only $15 \%$ of all articles on PO were dedicated to this topic, from 1991-2010 almost 40\% were about related social issues (Percentage 1979-1990 $_{19}$ Percentage $\left._{1991-2000,} p<0.05\right)$. Then, in the $2010-2017$ period, more than $50 \%$ of all articles on PO were about this theme (Percentage $2001-2010<$ Percentage $\left._{2011-2017}, p<0.05\right)$. We know that, similar to environmental concerns in their ability to attract increased focus, social concerns about PO became quite important (especially after 2000) following a decade of significant development in tropical areas (Oosterveer, 2015). Consequently, PO was related to land conflicts and tensions within communities and to human right abuses, such as child and forced labour (Boons and Mendoza, 2010; D'Antone and Spencer, 2014, 2015). To this end, we are not implying any causal relationship between facts and media discussions. For instance, it is possible that the media just reported certain specific news, and it could even be possible that the media spike prompted the protests. What we observe is that some trends seem to be interestingly related to one another, which made us want to better understand how this field is evolving over time. In the next section, we do this by running a linguistic analysis.

\subsection{Linguistic analysis}


In the previous section, we were concerned with the emerging themes related to PO. In the next three sub-sections, we investigate how journalists used these topics strategically. We do this by performing analyses of drives, writing styles and stakeholders.

\subsubsection{Drives analysis}

According to Higgins's (1997) regulatory focus theory, two alternative drives may guide people's behaviours. A 'reward' drive is typical of people who are promotion-oriented and tend to focus on accomplishments, aspirations and gains, while a 'risk' drive is common in people who are prevention-oriented and tend to concentrate on losses, responsibilities and safety. As LIWC includes one dictionary for each of these basic drives (Pennebaker et al., 2015), we could test their distinct roles in relation to our four main themes.

[Please Insert Table 4 About Here]

In examining Table 4, we can see that the economic theme is positively correlated with a reward drive $(r=0.15, p<0.01)$. Conversely, the environment $(r=0.07, p<0.01)$, health $(r=$ $0.05, p<0.01)$ and social $(r=0.08, p<0.01)$ themes are positively correlated with a risk orientation. This creates a clear distinction between the economic frame, which is more related to the promotion of positive outcomes associated with PO, and the environmental, health and social frames, which are mostly associated with the prevention of negative consequences related to PO. Next, we focus on the writing style analysis.

\subsubsection{Writing style analysis}

Following common practices in the literature (Pennebaker et al., 2015; Tausczik and Pennebaker, 2010), we wanted to check whether an analytical (i.e. formal and logical) instead of a narrative (i.e. more informal and personal) style was used differently in association with alternative frames. Specifically, we measured the 'analytical style' variable using the 'analytical thinking' dictionary available in LIWC and the 'narrative style' dimension by averaging the 
'pronouns' and 'auxiliary verbs' variables (again available in LIWC). According to Pennebaker (2017), these are two excellent proxies to identify narrative styles.

Using this approach, as illustrated in Table 4, we can observe that while the economic theme is positively correlated with a more analytical style $(r=0.13, p<0.01)$, the environmental $(r=-$ $0.06, p<0.01)$ and health $(r=-0.11, p<0.01)$ themes are negatively correlated with it. Furthermore, while the economic theme is negatively correlated with a more narrative style $(r=-$ $0.10, p<0.01)$, the environmental $(r=0.09, p<0.01)$ and social $(r=0.04, p<0.01)$ themes are positively correlated with it. Notably, while the analytical style tends to decrease over time $(r=-$ $0.17, p<0.01)$, the narrative style increases $(r=0.21, p<0.01)$. Thus, the longitudinal changes in themes we illustrated above are accompanied by a change from an analytical to a narrative style.

In interpreting these results, we conclude that the economic, promotional perspective is probably targeted at companies operating in the PO market (e.g. big processing and trading groups, manufacturers, etc.). Indeed, this discourse especially emphasises positive outcomes of PO and uses a more analytical style, which — as shown by the quotation below—may imply the provision of market data that are particularly insightful for firms:

Malaysia, the world's largest producer and exporter of palm oil, will increase its production of the commodity. The Primary Industries Minister told reporters that production is expected to reach 5.3 million tons a year by 1990 and 7.5 million tons a year by 2000. Last year, Malaysia produced 4.54 million tons of crude palm oil, and last year's palm oil exports earned the country 3.6 billion ringgits ( $\$ 1.44$ billion), $6.1 \%$ more than in the previous year. The higher value was due chiefly to higher world prices for the oil. Malaysia currently produces more than 50\% of the world's palm oil but accounts for approximately $80 \%$ of the world's palm oil exports (Source: Journal of Commerce; January 26, 1988). 
Conversely, the emergence of a second viewpoint that is more focused on prevention seems to suggest that one part of public opinion is attempting to make companies operate in a different way. As shown by the next quotation, the language used in these cases tends to mention critical issues and to adopt a more narrative style:

\author{
The United States Department of Labor Report 2014 lists Malaysia as a \\ country that practises child labour and forced labour in the palm oil \\ industry. The minister made it clear Malaysia did not condone any act of \\ forced labour or child labour, and the government viewed the US DOL \\ allegations and findings seriously. It also said the palm oil industry was one \\ of the most highly regulated industries in the country. The ministry said the \\ industry subscribed to more than 60 laws and regulations, including those \\ pertaining to labour practices (Source: New Straits Times; December 4, \\ 2014).
}

In this regard, we assume that environmental and social topics are communicated using less analytical language to capture the attention of more stakeholders and go beyond the interests of particular audiences. Moreover, to better illustrate how the various themes are associated with distinct actors, we related the various PO debates to the different stakeholders to which they could be directed. We describe this test in the next section.

\title{
5.2.3 Stakeholder analysis
}

To perform this analysis, we started by identifying the most salient stakeholders in the PO market. Building on several previous works (Boons and Mendoza, 2010; Coong and McKay, 2014; Oosterveer, 2015; Von Geibler, 2013), we focused on consumers, manufacturers, NGOs, retailers, smallholders, trading groups and public interest groups. The last category actually does not refer to a specific stakeholder. Rather, we included it to explore whether certain texts more broadly referred to general interests by using generic keywords such as 'individuals' or 'people' 
(see Table 2 for more details). Thereafter, we examined how these variables are associated with our themes of interest.

Table 5 shows that the economic theme positively correlates with numerous stakeholders, such as consumers $(r=0.17, p<0.01)$, manufacturers $(r=0.08, p<0.01)$, NGOs $(r=0.14, p<$ $0.01)$ and retailers $(r=0.13, p<0.01)$ but negatively correlates with public interest $(r=-0.05, p<$ 0.01). Conversely, the environmental theme positively correlates with NGOs $(r=0.07, p<0.01)$, public interest $(r=0.08, p<0.01)$ and retailers $(r=0.05, p<0.01)$. The social theme is positively associated with NGOs $(r=0.07, p<0.01)$, public interest $(r=0.10, p<0.01)$ and smallholders $(r$ $=0.06, p<0.01)$, while the health theme is positively associated with consumers $(r=0.15, p<$ $0.01)$ and manufacturers $(r=0.16, p<0.01)$.

[Please Insert Table 5 About Here]

These findings suggest that the economic theme, which is mostly related to the promotion of positive outcomes, is not only discussed using a more analytical writing style but also refers to many particular stakeholders, such as consumers or retailers, and not to the public interest. Based on Suchman (1995)'s definition, this implies that this discourse may be related to pragmatic legitimacy. Conversely, the environmental and social themes, which are associated with the prevention of negative outcomes, are discussed using a more narrative writing style and are used to talk in terms of public interest. This indicates that these two frames represent an alternative view to the previous one that, based on Suchman (1995)'s definition, we may associate with moral legitimacy.

The environmental theme is also associated with retailers, while the social theme is directly related to smallholders. However, the most important finding of our analysis is that, unlike the economic theme, both these themes significantly relate to public interest. In contrast to our expectations, this does not happen for the health theme, which is related to the prevention of 
negative outcomes (i.e. risk drive), but is not associated with public interest, unlike the socioenvironmental topics. Moreover, its importance tends to decrease over time, while - as observed above - both the environmental and social themes are becoming increasingly salient. It is thus evident that trends associated with health discussions are different by both the economic and the socio-environmental frames. We will elaborate on this issue in the final discussion.

\subsection{Producing vs. consuming countries' analysis}

To complete our empirical investigation, we tested how the legitimacy struggles of interest in this paper involve international relations. As in other institutional works (e.g. Scherer and Palazzo, 2011), it is relevant to try to unravel the complex national and international aspects involved. While other contributions have focused on, for instance, countries' historical roots, the global North/South division or the development of global governance and democracy (Joutsenvirta and Vaara, 2015), we paid particular attention to the different roles played by the countries in the PO market. We analysed whether topics associated with pragmatic legitimacy could more directly relate to producing countries that can benefit from the economic development of the PO industry and whether themes related to moral legitimacy could be more relevant for consuming countries that are concerned about the potentially dangerous consequences of PO use.

To perform this analysis, we divided the publications included in our sample into two groups (see Appendix C). The first group of articles mentions all the countries in our sample in which PO is produced (i.e. Brazil, Ghana, Malaysia, Nigeria). The second group mentions all the countries in our sample in which PO is not produced but only consumed (i.e. Australia, Bangladesh, Canada, EU-27, Hong Kong, Japan, New Zealand, Pakistan, Saudi Arabia, Singapore, South Africa, United Arab Emirates, US). Notably, the countries mentioned in the first group are responsible for $31.71 \%$ of global PO production, while the countries mentioned in the second group are responsible for $23.37 \%$ of global PO consumption ${ }^{7}$. We then verified whether

\footnotetext{
${ }^{7}$ In this regard, it is important to remark that producing countries (e.g. Malaysia) are also consuming countries (see Appendix C). However, for our purpose, we distinguished them from countries that only consume PO.
} 
the two groups differed in their discussions of the four basic themes relating to PO and, as an additional check, investigated whether they differed in their use of language promoting or criticising PO.

\section{[Please Insert Figure 2 About Here]}

As Figure 2 clearly shows, the economic theme more directly relates to producing countries $\left(M_{\text {Producers }}=5.61>M_{\text {Consumers }}=4.74, p<0.001\right)$. Conversely, the environmental $\left(M_{\text {Producers }}=0.40\right.$ $\left.<M_{\text {Consumers }}=0.60, p<0.01\right)$ and health themes $\left(M_{\text {Producers }}=2.99<M_{\text {Consumers }}=3.54, p<0.001\right)$ are more significantly discussed in consuming countries. However, the social theme is similarly discussed $(p>0.05)$ in producing $\left(M_{\text {Producers }}=0.21\right)$ and consuming countries $\left(M_{\text {Consumers }}=0.24\right)$. Notably, a reward focus is more typical in places where PO is produced $\left(M_{\text {Producers }}=0.85>\right.$ $M_{\text {Consumers }}=0.69, p<0.001$, while a risk focus is more typical in places where it is only consumed $\left(M_{\text {Producers }}=0.35<M_{\text {Consumers }}=0.86, p<0.001\right)$. This final result confirms our main assumption that pragmatic legitimacy is mostly associated with producing countries, while moral legitimacy is more relevant in consuming countries. Next, we discuss the implications of our results.

\section{Discussion and implications}

We divided this section into four parts to better distinguish what our results may more generally mean in terms of PO legitimation, linguistic strategies, legitimacy theory and sustainability.

\subsection{Palm oil controversies and legitimacy struggles}

In this article, we carried out research that, to our knowledge, represents the first attempt to apply concepts from institutional theory to the specific context of the PO market. We believe this is an important contribution to the literature on PO (Hansen et al., 2015). As illustrated in Figure 
3, we showed that historical discussions on PO controversies frequently refer to four main topics - the economic, environmental, health and social impacts of PO. Furthermore, by performing a detailed linguistic analysis, we recognised two main discourses related to these frames. On one hand, we observed that the economic theme is mainly associated with rewards, is communicated using analytical language and directly relates to specific stakeholders, such as consumers, manufacturers, NGOs and retailers. We thus conceptualised this as a way to link PO to pragmatic legitimacy (Suchman, 1995). On the other hand, the environmental and social frames are mostly associated with risks, are discussed using narrative language and more generally refer to public interest. We therefore interpreted this alternative discourse as more related to moral legitimacy (Suchman, 1995).

The health frame, instead, seems to share certain aspects with pragmatic legitimacy and others with moral legitimacy. Similar to pragmatic legitimacy and unlike moral legitimacy, it is associated with specific stakeholders, such as final consumers. We interpret this result by considering that media discussions about health were especially important before 2000, when PO production and consumption were directly associated with specific needs of various actors, such as manufacturers (interested in economic issues) and final consumers (worried about health problems). Consistent with this view, our data shows how, although with some geographic exceptions, the discussion of health problems became less important once the discourse started considering public interest to a greater extent. Further, similar to moral legitimacy and unlike pragmatic legitimacy, health is linked to a prevention motivation. We therefore argue that, in our period of interest, the prevention perspective has been associated with three alternative themes (i.e. environmental, health, and social issues) that garnered differing degrees of attention over time. That is, before 2000 , prevention issues were predominantly related to health themes, as shown by the American campaign against tropical oils (McNamara, 2010; Nordin et al., 2010). After 1990, the significant development of the PO market and its potential impact on socioenvironmental issues (Oosterveer, 2015) and the shift toward public interest caused a change in 
the media discourse, which, especially since 2000 , started relating prevention less to health and more to these two emerging dimensions.

Based on our longitudinal analysis, we can thus corroborate the contributions of previous scholars who showed that legitimation is a complex process (Humphreys, 2010; Johnson et al., 2006; Suddaby et al., 2016) through which the same object (in our case PO) can be associated with different meanings and alternative types of legitimacy over time (Deephouse et al., 2017; Mahadeo et al., 2011). Indeed, especially in contested markets such as that of PO (Rival and Levang, 2014), it is likely that continuous criticism of the object of interest generates some struggles that then open the door to the development of new meanings and types of legitimacy (Joutsenvirta and Vaara, 2015; Luyckx and Janssens, 2016; Suddaby and Greenwood, 2005). In our study, we showed how the emergence of alternative topics and the way they have been communicated (i.e. the linguistic strategies used by journalists) have made different issues salient and thus required potentially different strategies to legitimate PO. For instance, when the economic theme and related rewards, together with the adoption of an analytical style and attention to specific stakeholders, became noticeable in the media, companies were mainly expected to build pragmatic legitimacy. Conversely, especially after the extension of oil palm plantations into tropical areas in the 1990s (Oosterveer, 2015), other topics, such as environmental and social issues, were discussed more by newspapers. Journalists also focused more on how to prevent risks (Higgins, 1997), used a narrative style and mentioned public interest more often. Accordingly, they started considering pragmatic legitimacy as no longer sufficient and, simultaneously, implied that moral legitimacy was the new objective companies were expected to achieve. In this regard, Scherer and Palazzo (2011, p. 906) suggest that 'in order to respond to the globalisation phenomenon and the emerging post-national constellation, it is necessary to acknowledge a new political role of business that goes beyond mere compliance with legal standards and conformity with moral rules'. 
To sum up, it is important to highlight that the two main logics that have emerged and alternated in the context of PO controversies (pragmatic vs. moral) combine two elements. They do not only refer to certain contrasting topics (e.g. economic vs. environmental) but are also conveyed through different linguistic strategies. We elaborate more on this in the next section.

\subsection{Legitimacy struggles and linguistic strategies}

To analyse the linguistic strategies applied in our context of analysis, we conducted an automated content analysis (Humphreys and Wang, 2018) that made it possible to look at both the content and the style of communication of PO debates (Pennebaker et al., 2015). Following previous works (e.g. Tausczik and Pennebaker, 2010), we examined the topics most often associated with PO and the linguistic strategies used to communicate them. Our original method helped us to both demonstrate the fundamental role of linguistic strategies in legitimation processes (e.g. Vaara and Tienari, 2008) and to quantitatively measure their trends, which represents a relevant difference compared with other institutional analyses that usually adopt qualitative approaches (Joutsenvirta and Vaara, 2015; Maguire and Hardy, 2009; Vaara et al., 2006).

We found that, when criticism about PO started becoming evident and socio-environmental themes more prominent, the communication style used by journalists changed. First, it tended to be more narrative and less analytical. Narrativisation, in fact, is considered a specific linguistic strategy 'for giving concrete meaning to the rational or moral bases of the phenomenon at hand' (Vaara et al., 2006, p. 805). Second, there was a switch in the main motivation expressed by journalists, which in the case of economic issues was more consistent with a promotion perspective and, in the case of environmental, health and social issues, was more associated with a prevention orientation. We believe this change in drive can be deemed another linguistic strategy that was used here in conjunction with narrativisation and that was not considered in previous works (e.g. Vaara et al., 2006). We believe that the identification of this second linguistic strategy, 
which consists of discussing certain themes by making different drives salient (Higgins, 1997), can be considered another potential contribution of our work.

Third, we showed that, depending on the addressed topic, different attention was paid to the various PO stakeholders. We demonstrated that, while the economic and health issues were usually related to several, specific actors, the environmental and social ones were more significantly related to general, public interest. By linking our work with that of Chiles (2017), we might even speculate that the decreased attention to specific issues and stakeholders in favour of a more general, socio-environmental narrative may actually be the fulfilment of a third strategy. According to construal level theory (Trope and Liberman, 2010), shifting from individual health issues to environmental and social topics could be considered safer because it creates more psychological distance between final consumers and their (problematic) object of interest (e.g. health issues related to PO consumption). Thus, final consumers would ultimately pay more attention to universal issues, such as socio-environmental themes, which would make them less concerned about the potentially negative consequences for themselves. However, more research is needed to better understand the potential relationships between risk perceptions and psychological distance (e.g. Lermer et al., 2016).

\subsection{Legitimacy struggles and international trends}

In our work, we also illustrated that legitimacy struggles involve international relations (Joutsenvirta and Vaara, 2015). This was especially evident when comparing the media coverage in producing and consuming countries. In particular, while pragmatic legitimacy seemed to be more relevant in producing countries, moral legitimacy tended to be considered as key in consuming countries. This means that producers working in the PO market should pay particular attention to moral themes if they want to be legitimated in the marketplace and want to defend themselves against the criticism of PO and its production. Some recent actions, such as those of the RSPO, show that socio-environmental issues are increasingly taken into consideration in PO production and distribution. Nevertheless, certain authors (e.g. Von Geibler, 2013) observe a 
continuous criticism of RSPO on the part of NGOs, which suggests that RSPO has not yet been able to achieve the required level of moral legitimacy. This indicates that while the process of obtaining this type of legitimacy has started, it needs to be better developed to satisfy the emerging needs of public opinion.

Our empirical work has several implications in this regard. In considering the three pillars of sustainability (i.e. the economic, environmental and social dimensions), we saw how the economic theme is more important for PO-producing countries than for PO-consuming countries (Boons and Mendoza, 2010), while the social issues are not significantly different. In looking at environmental topics, we then demonstrated that consuming countries tend to pay more attention to them. Therefore, one key insight of our analysis is that it might be especially helpful to invest in environmental actions, which are particularly stressed by consuming countries, in order for producing countries to be better accepted by consuming ones.

Another important implication relates to the idea that consuming countries are significantly interested in health issues associated with PO consumption. This seems to contradict what we observed in longitudinal trends, which showed the decreasing importance of the health aspect over time. However, if we distinguish between producing and consuming countries and notice what is happening in Europe, for instance, we see how a growing number of companies are now offering PO-free products due to increasing health concerns (Hucal, 2015). As detailed above, the health theme also became a major challenge in the US, another PO-consuming country, particularly during the 1980s and 1990s (Nordin et al., 2010). We therefore maintain that, while the increasing attention to socio-environmental concerns (which is typical of the RSPO, for instance) may be deemed appropriate to respond to the request to focus on moral legitimacy, the insufficient consideration of health concerns might become another issue to take into account. This is also shown by the criticism directed at the RSPO itself for not adequately addressing this problem (D’Antone and Spencer, 2015). Accordingly, we stress the importance of paying more attention to 
this issue and of producing new research that specifically focuses on the understudied effects of health concerns on consumers' attitudes towards PO (Disdier et al., 2013).

\subsection{Palm oil controversies and sustainability}

In more general terms, in this and similar contexts (Benites-Lazaro and Mello-Théry, 2017; Luyckx and Janssens, 2016) we suggest it is becoming essential for companies to pay attention to what is 'the right thing to do' in terms of overall public good (Suchman, 1995) to achieve a more defensible level of legitimacy (Pavlovich et al., 2016). Firms, in particular, are increasingly recognised as members of a broader social and institutional context; therefore, they may reach this objective only if they show that they are sustainable actors in the field in which they operate. Nevertheless, as also noted by other authors (Dendler, 2014; Kemper and Partzsch, 2018; Roman, 2017), sustainability may acquire alternative meanings in different settings. In other words, discussions of sustainability issues may refer to different pillars (e.g. economic vs. environmental) depending on the specific spatio-temporal conditions in which the construct is applied (Joutsenvirta, 2011; Joutsenvirta and Vaara, 2015).

Our analysis contributes to this stream of research by showing that the various themes related to PO provide alternative perspectives for the social construction of sustainability meanings. For example, the economic issues related to PO (e.g. costs, profits, etc.) have been considered less important up until 2010, at which time they started becoming newly salient. Currently, while they still remain key for producing countries, economic issues are not particularly stressed by countries in which PO is only consumed. Conversely, the environmental issues (e.g. deforestation, waste, etc.) have been deemed increasingly fundamental and particularly critical for consuming countries, which pay more attention to the environmental problems potentially caused by PO production. The social issues (e.g. human rights, poverty, etc.) also tend to be mentioned more often over time, but their importance does not seem to vary between producing and consuming countries. 
Accordingly, we believe our study provides insights that can help policy makers and organisations to increase the uptake of sustainable PO. Based on our results, we imagine two alternative discourses that may currently be associated with the promotion of sustainable PO in different geographic areas. For what concerns producing countries, our analysis suggests relating the idea of sustainability to economic development and social issues. Therefore, one potential argument to support sustainable PO could be that the development of this market may significantly help emerging economies to grow and local communities to overcome important social problems, such as poverty. We also believe that, in consuming countries, an alternative discourse could better highlight the socio-environmental advantages of choosing sustainable PO. On one side, this may mean showing how problems related to deforestation, biodiversity or climate change could be more effectively addressed by choosing to use sustainable PO. On the other side, this may mean showing how supply chains in the production of sustainable PO can guarantee better work conditions and the defence of human rights in general. Although it is less related to socio-environmental sustainability, it is finally important to remark that, as noted above, communication in consuming countries should adequately consider the significant concerns about health issues. This may mean providing stakeholders with additional information, such as scientific evidence that no proof exists about the effects of PO consumption on human health compared to other saturated fats (e.g. Marangoni et al., 2017).

\section{Limitations and recommendations for future research}

We believe that to better comprehend the overall picture regarding legitimacy struggles relating to $\mathrm{PO}$, it is crucial to examine how other mechanisms that we did not directly consider in our study might also have affected the above trends. For example, food companies' corporate social responsibility reports, websites and social media pages could be explored to understand how firms have changed their communication about PO over time. Other media, such as websites, 
blogs or forums dedicated to discussing PO issues could also be investigated to identify their influence.

It is also important to recognise that, while we did refer to some distinctions about geographic areas, we did not have room to conduct a deeper analysis of how different countries have distinctively discussed the topic of PO. In this regard, it is important to consider that, by doing a keyword search on the topic of PO, we did not extract a balanced sample, which would have made it possible to run more accurate comparisons. For instance, a first potential source of selection bias is the inclusion of a limited set of countries in the sample, which are those countries with full-text access to their publications in the LexisNexis database (see also Kananovich, 2018 for similar issues). Although this potential bias is mitigated by the fact that we considered geographic areas that both produce and/or consume PO (see Appendix C), future research might focus on other countries and extract a more representative sample to do more reliable comparisons.

Another potential bias relates to our decision to only focus on English-language data. While this strategy may make sense if the research objective is to examine the international discourses on one specific topic, as is commonly done in similar research (see Kananovich, 2018), this may also create potential issues. For instance, in geographic areas in which English is not the first language, news articles written in English could be targeted at international rather than domestic readers, making the domestic issues less salient. Therefore, including non-English publications in the empirical analysis might make it easier to illustrate different discussions about PO that take place around the world at a local level.

Regarding our thematic analysis, we also have to acknowledge that we only focused on general themes related to PO, such as economic, environmental and social issues. We did not run analyses on more specific sub-themes because we did not have room to do a more detailed investigation and because in this study we particularly aimed at exploring the main frames associated with this complex subject. However, future research could enlighten our results by 
distinguishing more particular categories, such as greenhouse gas emissions, deforestation and human rights and determining how they relate to the other constructs we examined. This further analysis could also shed more light on the health frame, which, according to our data, seems to be related to both pragmatic and moral legitimacy. More detailed analyses of this frame could explore whether specific aspects of the health issue are more associated with pragmatic legitimacy (e.g. discussions about how PO consumers may be susceptible to health problems such as cardiovascular diseases) and others are more consistent with moral legitimacy (e.g. discussions about how to prevent health issues for local workers and animals).

Finally, it is possible that doing an analysis at the journal level offers additional insights. For instance, the publications' circulation or focus (e.g. industry, academic, populist, etc.) may be differently related to the themes (e.g. economic, environmental, etc.) and rhetoric used by journalists (e.g. reward vs. risk). Writers themselves may also have different styles depending on their gender, which we were not able to know for all our sources. Therefore, future studies might try to build a more balanced sample that includes publications from different parts of the world and that represent alternative perspectives to examine their distinct power and ability to change institutional logics. Future studies might also use additional LIWC dictionaries to measure other variables (e.g. cognitive, perceptual or social processes) and to more fully analyse the evolution of linguistic strategies in this domain.

\section{Conclusions}

In this article, we started with the fact that PO is an ingredient largely used by companies in the food, energy and cosmetics industries and discussed how the emergence of several controversies relating to PO have jeopardised its legitimacy. Nevertheless, we noted that PO is a rare topic of discussion within the context of the literature on legitimacy struggles. In particular, we observed that, while research on PO residue remains the dominant stream in this field, the contributions on non-residue topics are increasingly calling attention to equally relevant PO- 
related issues. Our aim therefore became to provide a new perspective on PO by examining the legitimacy struggles that have emerged in this domain and by identifying and quantifying changes in the PO debate over time. Based on an automated content analysis of 3,713 global newspaper articles downloaded from LexisNexis covering the period 1979-2017, we obtained critical insights about how often different themes are mentioned in relation to the PO market (i.e. the economic, environmental, health and social impacts of PO) and how three specific linguistic strategies are implemented by the media in their coverage (i.e. focus on promotion vs. prevention motivations, adoption of analytic vs. narrative writing styles and reference to specific vs. general stakeholders). This way, we showed that two alternative types of legitimacy emerge and are objects of struggle in this domain; one focuses on pragmatic legitimacy and the other on moral legitimacy. In particular, we saw that pragmatic legitimacy is losing importance in favour of moral legitimacy over time and that pragmatic legitimacy remains key for PO-producing countries, while moral legitimacy is more significant for PO-consuming countries. We then detailed some implications in terms of PO legitimation, linguistic strategies, legitimacy theory and sustainability issues.

We believe this study may serve as a starting point for in-depth research on PO legitimacy struggles. Additionally, we think we have offered a few insights for companies, their stakeholders and researchers to evaluate the status of the PO debate and the legitimacy struggles that are occurring in this context. Specifically, by adopting such a critical and historical viewpoint, we believe our study has shed more light on this topic and that it provides policy makers and organisations with key inputs to more effectively develop the demand for sustainable PO. We hope our empirical analysis can thus inspire other researchers interested in better defining the meanings associated with sustainability in different settings and at specific points in time. Indeed, we strongly believe that longitudinally tracking what the public thinks about this or similar issues (as we tried to do in this article) is a key activity that may substantially help to increase the uptake of sustainable products. 


\section{References}

Benites-Lazaro, L.L., Mello-Théry, N.A., 2017. CSR as a legitimatizing tool in carbon market: Evidence from Latin America's clean development mechanism. J. Clean. Prod. 149 (February), 218-226.

Boons, F., Mendoza, A., 2010. Constructing sustainable palm oil: How actors define sustainability. J. Clean. Prod. 18 (16), 1686-1695.

Chapman, B., 2017. Could Nutella really cause cancer? Here's what you need to know. http://www.independent.co.uk/news/business/news/nutella-does-it-cause-cancer-spreadchocolate-nut-italy-supermarkets-palm-oil-carcinogenic-risk-a7523851.html (accessed February 20, 17).

Chiles, R.M., 2017. Hidden in plain sight: How industry, mass media, and consumers' everyday habits suppress food controversies. Sociol. Rural. 57 (1), 791-815.

Chong, Y.H., Ng, T.K., 1991. Effects of palm oil on cardiovascular risk. Med. J. Malaysia 46 (1), $41-50$.

Choong, C.G., McKay, A., 2014. Sustainability in the Malaysian palm oil industry. J. Clean. Prod. 85 (December), 258-264.

Corciolani, M., Gistri, G., Pace, S., 2016. Exploring the palm oil crisis through the lens of different social media: An analysis of Facebook, Youtube and Twitter contents. Mercati e Competitività, The J. of the Italian Marketing Assoc., 4, 43-64.

D'Antone, S., Spencer, R., 2014. Concerns and marketization: The case of sustainable palm oil, in: Geiger, S., Harrison, D., Kjellberg, H., Mallard, A. (Eds.), Concerned Markets Economic Ordering for Multiple Values. Edward Elgar Publishing, Cheltenham, pp.72-101.

D’Antone, S., Spencer, R., 2015. Organising for sustainable palm oil consumption: A marketbased approach. Consum. Markets and Culture, 18 (1), 55-71.

Deephouse, D.L., 1996. Does isomorphism legitimate? Acad. Manag. J. 39 (4), 1024-1039. 
Deephouse, D.L., Bundy, J., Tost, L.P., Suchman, M.C., 2017. Organizational legitimacy: Six key questions, in: Greenwood, R., Oliver, C., Lawrence, T., Meyer, R. (Eds.), The SAGE Handbook of Organizational Institutionalism, second ed. Sage, Thousand Oaks, pp. 27-54.

Dendler, L., 2014. Sustainability meta labelling: An effective measure to facilitate more sustainable consumption and production? J. Clean. Prod. 63 (January), 74-83.

Disdier A.C., Marette, S., Millet, G., 2013. Are consumers concerned about palm oil? Evidence from a lab experiment. Food Policy 43 (December), 180-189.

Dowling, J., Pfeffer, J., 1975. Organizational legitimacy: Social values and organizational behavior. Pac. Sociol. Rev. 18 (1), 122-136.

Ertimur, B., Coskuner-Balli, G., 2015. Navigating the institutional logics of markets: Implications for strategic brand management. J. of Marketing 79 (2), 40-61.

Gamson, W.A., Croteau, D., Hoynes, W., Sasson, T., 1992. Media images and the social construction of reality. Ann. Rev. of Sociol. 18 (1), 373-393.

Gassler, B., Spiller, A., 2018. Is it all in the MIX? Consumer preferences for segregated and mass balance certified sustainable palm oil. J. Clean. Prod. 195 (September), 21-31.

Gillespie, P., 2012. The challenges of corporate governance in Indonesian oil palm: Opportunities to move beyond legalism? Asian Stud. Rev. 36 (2), 247-269.

Glaser, B.G., Strauss, A.L., 1967. The Discovery of Grounded Theory: Strategies for Qualitative Research. Aldine, Chicago.

Hansen, S.B., Padfield, R., Syayuti, K., Evers, S., Zakariah, Z., Mastura, S., 2015. Trends in global palm oil sustainability research. J. Clean. Prod. 100 (August), 140-149.

Higgins, E.T., 1997. Beyond pleasure and pain. Am. Psych., 52 (12), 1280-1300.

Hoffman, A.J., 1999. Institutional evolution and change: Environmentalism and the U.S. chemical industry. Acad. Manag. J. 42 (4), 351-371.

Hucal, S., 2015. The Italians fighting against an "invasion” of palm oil. https://www.theguardian.com/sustainable-business/2015/dec/09/italy-italian-food-palm-oil- 
supermarkets-boycott-deforestation-forests-health-environment-china-alliances (accessed April 20, 2017).

Humphreys, A., 2010. Megamarketing: The creation of markets as a social process. J. of Marketing 74 (2), 1-19.

Humphreys, A., Latour, K.A., 2013. Framing the game: Assessing the impact of cultural representations on consumer perceptions of legitimacy. J. Consumer Res. 40 (4), 773-795.

Humphreys, A., Wang, R.J.H., 2018. Automated text analysis for consumer research. J of Consumer Res. 44 (6), 1274-1306.

Jamaludin, N.F., Hashim, H., Ab Muis, Z., Zakaria, Z.Y., Jusoh, M., Yunus, A., Murad, S.M.A., 2018. A sustainability performance assessment framework for palm oil mills. J. Clean. Prod. 174 (February), 1679-1693.

Johnson, C., Dowd, T.J., Ridgeway, C.L., Cook, K.S., Massey, D.S., 2006. Legitimacy as a social process. Ann. Rev. of Sociol., 32 (1), 53-79.

Joutsenvirta, M., 2011. Setting boundaries for corporate social responsibility: Firm-NGO relationship as discursive legitimation struggle. J. of Bus. Ethics 102 (1), 57-75.

Joutsenvirta, M., Vaara, E., 2015. Legitimacy struggles and political corporate social responsibility in international settings: A comparative discursive analysis of a contested investment in Latin America. Organ. Stud. 36 (6), 741-777.

Kananovich, V., 2018. Framing the taxation-democratization link: An automated content analysis of cross-national newspaper data. The Intern. J. of Press/Politics. 32 (2), 1-21.

Kemper, L., Partzsch, L., 2018. A water sustainability framework for assessing biofuel certification schemes: Does European hybrid governance ensure sustainability of palm oil from Indonesia? J. Clean. Prod. 192 (August), 835-843.

Lermer, E., Streicher, B., Sachs, R., Raue, M., Frey, D. 2016. Thinking concretely increases the perceived likelihood of risks: The effect of construal level on risk estimation. Risk Anal. 36 (3), 623-637. 
Luyckx, J., Janssens, M., 2016. Discursive legitimation of a contested actor over time: The multinational corporation as a historical case. Organ. Stud. 37 (11), 1595-1619.

Maguire, S., Hardy, C., 2009. Discourse and deinstitutionalization: The decline of DDT. Acad. Manag. J. 52 (1), 148-178.

Mahadeo, J.D., Oogarah-Hanumana, V., Soobaroyenb, T., 2011. Changes in social and environmental reporting practices in an emerging economy (2004-2007): Exploring the relevance of stakeholder and legitimacy theories. Account. Forum. 35 (3), 158-175.

Marangoni, F., Galli, C., Ghiselli, A., Lercker, G., La Vecchia, C., Maffeis, C., Agostoni, C., Ballardini, D., Brignoli, O., Faggiano, P., Giacco, R., Macca, C., Magni, P., Marelli, G., Marrocco, W., Miniello, V.L., Mureddu, G.F., Pellegrini, N., Stella, R., Troiano, E., Verduci, E., Volpe, R., Poli, A. 2017. Palm oil and human health. Meeting report of NFI: Nutrition Foundation of Italy symposium. Int. J. Food. Sci. Nutr. 68(6), 643-655.

Matthes, J., Kohring, M., 2008. The content analysis of media frames: Toward improving reliability and validity. J. of Commun. 58 (2), 258-279.

McNamara, D.J., 2010. Palm oil and health: A case of manipulated perception and misuse of science. J. of the Am. Coll. of Nutr. 29 (3), 240-244.

Meyer, J.W., Rowan, B., 1977. Institutionalized organizations: Formal structure as myth and ceremony. Am. Sociol. Rev. 83 (2), 340-363.

Montecchia, A., Giordano, F., Grieco, C., 2016. Communicating CSR: Integrated approach or selfie? Evidence from the Milan Stock Exchange. J. Clean. Prod. 136 (November), 42-52.

Nordin, A.B.A., Simeh, M.A., Mahidin, M.R., Shariff, F.M., 2010. Impact of labelling on palm oil in the US market. Palm Oil Dev. 52, 5-9.

Oosterveer, P., 2015. Promoting sustainable palm oil: Viewed from a global networks and flows perspective. J. Clean. Prod. 107 (November), 146-153. 
Pavlovich, K., Sinha, P.N., Rodrigues, M. 2016. A qualitative case study of MNE legitimacy: The Fonterra-Sanlu IJV corporate milk scandal in China. Intern. J. of Emerg. Markets. 11 (1), $42-56$.

Pennebaker, J., 2017. Mind mapping: Using everyday language to explore social and psychological processes. Proced. Computer Sci. 118 (December), 100-107.

Pennebaker, J.W., Francis, M.E., Booth, R.J., 2007. Linguistic Inquiry and Word Count (Liwc): Liwc2007. Lawrence Erlbaum Associates, Mahwah.

Pennebaker, J.W., Boyd, R.L., Jordan, K., Blackburn, K., 2015. The Development and Psychometric Properties of LIWC2015. University of Texas at Austin, Austin.

Reijnders, L., Huijbregts, M.A.J., 2008. Palm oil and the emission of carbon-based greenhouse gases. J. Clean. Prod. 16 (March), 477-482.

Rival, A., Levang, P., 2014. Palms of Controversies: Oil Palm and Development Challenges. Center for International Forestry Research, Bogor Barat.

Roman, A.V., 2017. Institutionalizing sustainability: A structural equation model of sustainable procurement in US public agencies. J. Clean. Prod. 143 (February), 1048-1059.

RSPO, 2004. Statutes. RSPO, Zurich.

Saswattecha K., Kroeze, C., Jawjit, W., Hein, L., 2017. Improving environmental sustainability of Thai palm oil production in 2050. J. Clean. Prod. 147 (March), 572-588.

Scherer, A.G., Palazzo, G., 2011. The new political role of business in a globalized world: A review of a new perspective on CSR and its implications for the firm, governance, and democracy. J. Manag. Stud. 48 (4), 899-931.

Scott, W.R., 2001. Institutions and Organizations: Ideas, Interests and Identities. Sage, Los Angeles.

Sethi, S.P., 1979. A conceptual framework for environmental analysis of social issues and evaluation of business response patterns. Acad. Manag. Rev. 4 (1), 63-74. 
Smith, J.S. 1998. The strange history of the decade: Modernity, nostalgia, and the perils of periodization. J. Soc. Hist. 32 (2), 263-285.

Suchman, M.C., 1995. Managing legitimacy: Strategic and institutional approaches. Acad. Manag. Rev. 20 (3), 571-610.

Suddaby, R., Bitektine, A., Haack, P., 2016. Legitimacy. Acad. Manag. Ann. 11 (1), 451-478.

Suddaby, R., Greenwood, R., 2005. Rhetorical strategies of legitimacy. Adm. Sci. Q. 50 (1), 3567.

Tamul, D.J., Martínez-Carrillo, N.I., 2017. Ample sample? An examination of the representativeness of themes between sampling durations generated from keyword searches for 12 months of immigration news from LexisNexis and newspaper websites. Journ. \& Mass Commun. Quart. 95 (1), 1-26.

Tausczik, Y.R., Pennebaker, J.W., 2010. The psychological meaning of words: LIWC and computerized text analysis methods. J. of Lang. and Soc. Psych. 29 (1), 24-54.

Trope, Y., Liberman, N., 2010. Construal-level theory of psychological distance. Psych. Rev. 117 (2), 440-463.

Vaara, E., Tienari, J., 2008. A discursive perspective on legitimation strategies in multinational corporations. Acad. Manag. Rev. 33 (4), 985-993.

Vaara, E., Tienari, J., Laurila, J., 2006. Pulp and paper fiction: On the discursive legitimation of global industrial restructuring. Organ. Studies, 27 (6), 789-810.

Vergragt, P.J., Dendler, L., de Jong, M., Matus, K., 2016. Transitions to sustainable consumption and production in cities. J. Clean. Prod. 134 (October), 1-12.

Von Geibler, J., 2013. Market-based governance for sustainability in value chains: Conditions for successful standard setting in the palm oil sector. J. Clean. Prod. 56 (October), 39-53. 
Table 1. Sources

\begin{tabular}{lccccc}
\hline & \multicolumn{5}{c}{ Decade } \\
\cline { 2 - 5 } & $1979-1990$ & $1991-2000$ & $2001-2010$ & $2011-2017$ & Total \\
\hline \multirow{2}{*}{ Africa } & 3 & 20 & 25 & 38 & 86 \\
& $(0.10 \%)$ & $(0.50 \%)$ & $(0.70 \%)$ & $(1.00 \%)$ & $(2.30 \%)$ \\
Asia & 54 & 409 & 1,072 & 940 & 2,475 \\
& $(1.50 \%)$ & $(11.00 \%)$ & $(28.90 \%)$ & $(25.30 \%)$ & $(66.70 \%)$ \\
Europe & 4 & 16 & 174 & 119 & 313 \\
& $(0.10 \%)$ & $(0.40 \%)$ & $(4.70 \%)$ & $(3.20 \%)$ & $(8.40 \%)$ \\
Latin America & 12 & 18 & 32 & 25 & 87 \\
& $(0.30 \%)$ & $(0.50 \%)$ & $(0.90 \%)$ & $(0.70 \%)$ & $(2.30 \%)$ \\
Middle East & 1 & 37 & 45 & 17 & 100 \\
& $(0.00 \%)$ & $(1.00 \%)$ & $(1.20 \%)$ & $(0.50 \%)$ & $(2.70 \%)$ \\
North America & 46 & 51 & 163 & 116 & 376 \\
\multirow{4}{*}{ Oceania } & $(1.20 \%)$ & $(1.40 \%)$ & $(4.40 \%)$ & $(3.10 \%)$ & $(10.10 \%)$ \\
& 2 & 33 & 92 & 149 & 276 \\
Total & $(0.10 \%)$ & $(0.90 \%)$ & $(2.50 \%)$ & $(4.00 \%)$ & $(7.40 \%)$ \\
\hline
\end{tabular}

Notes: The percentages in parentheses are calculated as the number of publications in that cell out of the total number of publications. For instance, there are 3 African publications in 1979-1990, which correspond to a percentage calculated as follows: $3 / 3,713=0.10 \%$ of the total. 
Table 2. Categories' definitions and keywords

\begin{tabular}{|c|c|c|c|c|}
\hline Categories & Definitions & $\begin{array}{l}\text { Words in } \\
\text { category }\end{array}$ & Examples & Alpha \\
\hline \multicolumn{5}{|c|}{ Palm oil themes } \\
\hline Economic & $\begin{array}{l}\text { The text discusses the } \\
\text { economic impacts of palm oil } \\
\text { market, e.g., by referring to } \\
\text { production details. }\end{array}$ & 171 & $\begin{array}{l}\text { Corporat*; customer*; } \\
\text { produc* }\end{array}$ & N.A. \\
\hline Environmental & $\begin{array}{l}\text { The text analyses the } \\
\text { environmental impacts of palm } \\
\text { oil, e.g., by referring to } \\
\text { deforestation. }\end{array}$ & 65 & $\begin{array}{l}\text { Emission*; forest; } \\
\text { vegetation }\end{array}$ & 91.67 \\
\hline Health & $\begin{array}{l}\text { The text considers the impact } \\
\text { of palm oil consumption on } \\
\text { human beings' health, e.g., by } \\
\text { referring to saturated fats. }\end{array}$ & 236 & Cardio*; obes*; eat & N.A. \\
\hline Social & $\begin{array}{l}\text { The text examines the social } \\
\text { impacts of palm oil, e.g., by } \\
\text { referring to human rights } \\
\text { abuses. }\end{array}$ & 49 & $\begin{array}{l}\text { Abuse; human rights; } \\
\text { poverty }\end{array}$ & 94.01 \\
\hline \multicolumn{5}{|c|}{ Stakeholders } \\
\hline Consumers & $\begin{array}{l}\text { The category captures text that } \\
\text { mentions consumers. }\end{array}$ & 4 & $\begin{array}{l}\text { Consumer*; } \\
\text { customer*; user* }\end{array}$ & 100.00 \\
\hline Manufacturers & $\begin{array}{l}\text { The category captures text that } \\
\text { mentions manufacturers. }\end{array}$ & 1 & Manufacturer* & 100.00 \\
\hline NGOs & $\begin{array}{l}\text { The category captures text that } \\
\text { mentions NGOs. }\end{array}$ & 1 & NGO* & 100.00 \\
\hline Public interest & $\begin{array}{l}\text { The category captures text that } \\
\text { mentions public interest. }\end{array}$ & 6 & $\begin{array}{l}\text { Civil; individual*; } \\
\text { people }\end{array}$ & 88.89 \\
\hline Retailers & $\begin{array}{l}\text { The category captures text that } \\
\text { mentions retailers. }\end{array}$ & 5 & $\begin{array}{l}\text { Distribut*; reseller*; } \\
\text { retailer* }\end{array}$ & 86.67 \\
\hline Smallholders & $\begin{array}{l}\text { The category captures text that } \\
\text { mentions smallholders. }\end{array}$ & 1 & Smallholder* & 100.00 \\
\hline Trading groups & $\begin{array}{l}\text { The category captures text that } \\
\text { mentions trading groups. }\end{array}$ & 1 & Trading group* & 100.00 \\
\hline
\end{tabular}

Notes: Each line illustrates a dictionary dimension. First, the category name is provided (e.g., economic), followed by our conceptual definition. Then, the number of keywords used to search that dimension in the texts, in addition to some exemplifying words (e.g., corporat*; customer*; produc*), are added. In particular, the asterisk at the end of "corporat*" captures all words that begin with "corporat" (e.g., corporate, corporations). Finally, the Alpha, which is the percent of agreement among three coders on dictionary words in the categories, is provided. This measure is not available for "economic" and "health" because these dictionaries were originally pretested by Pennebaker et al. (2015). 
Table 3. Thematic changes over time

\begin{tabular}{|c|c|c|c|c|c|c|c|c|}
\hline Theme & Africa & Asia & Europe & $\begin{array}{l}\text { Latin } \\
\text { America }\end{array}$ & $\begin{array}{l}\text { Middle } \\
\text { East }\end{array}$ & $\begin{array}{l}\text { North } \\
\text { America }\end{array}$ & Oceania & Total \\
\hline \multicolumn{9}{|l|}{ Economic } \\
\hline 1979-1990 & & 66.70 & & & & 69.60 & & 64.80 \\
\hline 1991-2000 & 35.00 & 50.60 & & & 40.50 & 49.00 & 60.60 & 50.30 \\
\hline 2001-2010 & 56.00 & 37.80 & 40.80 & 40.60 & 46.70 & 39.30 & 39.10 & 38.90 \\
\hline 2011-2017 & 44.70 & 50.00 & 52.10 & 28.00 & & 44.80 & 47.00 & 49.30 \\
\hline Total & 46.50 & 45.20 & 45.40 & 42.50 & 51.00 & 46.00 & 46.40 & 45.50 \\
\hline \multicolumn{9}{|l|}{ Environmental } \\
\hline 1979-1990 & & 14.80 & & & & 6.50 & & 9.80 \\
\hline $1991-2000$ & 0.00 & 23.70 & & & 2.70 & 3.90 & 3.00 & 18.30 \\
\hline 2001-2010 & 40.00 & 29.40 & 51.70 & 25.00 & 28.90 & 33.70 & 45.70 & 33.30 \\
\hline 2011-2017 & 55.30 & 38.90 & 24.40 & 36.00 & & 46.60 & 45.00 & 39.50 \\
\hline Total & 36.00 & 31.80 & 38.30 & 26.40 & 22.00 & 30.30 & 39.90 & 32.50 \\
\hline \multicolumn{9}{|l|}{ Health } \\
\hline 1979-1990 & & 51.90 & & & & 60.90 & & 54.10 \\
\hline 1991-2000 & 70.00 & 59.20 & & & 67.60 & 47.10 & 30.30 & 57.20 \\
\hline 2001-2010 & 32.00 & 37.40 & 31.60 & 40.60 & 37.80 & 28.20 & 50.00 & 36.60 \\
\hline 2011-2017 & 31.60 & 37.30 & 52.90 & 28.00 & & 28.40 & 37.60 & 37.50 \\
\hline Total & 39.50 & 41.30 & 40.30 & 44.80 & 47.00 & 34.80 & 40.90 & 40.70 \\
\hline \multicolumn{9}{|l|}{ Social } \\
\hline 1979-1990 & & 20.40 & & & & 13.00 & & 15.60 \\
\hline 1991-2000 & 5.00 & 49.40 & & & 2.70 & 9.80 & 15.20 & 37.50 \\
\hline 2001-2010 & 52.00 & 35.90 & 35.60 & 50.00 & 73.30 & 52.10 & 30.40 & 38.80 \\
\hline 2011-2017 & 44.70 & 60.50 & 42.00 & 40.00 & & 54.30 & 40.90 & 55.90 \\
\hline Total & 37.20 & 47.20 & 36.10 & 35.60 & 49.00 & 42.30 & 34.10 & 44.30 \\
\hline
\end{tabular}

Notes: Dependent variable $=($ Number of articles about a theme $/$ Number of articles in the period) $\times 100$. The data related to cells that have less than 20 articles are not reported. 


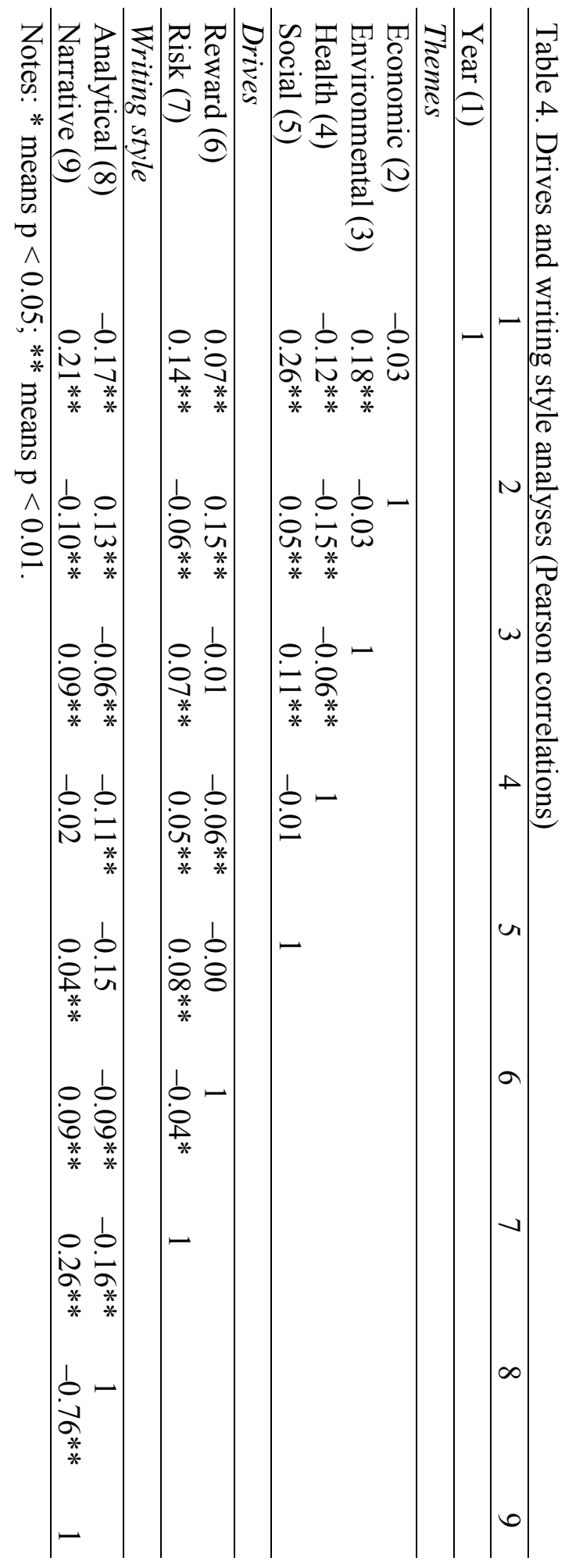




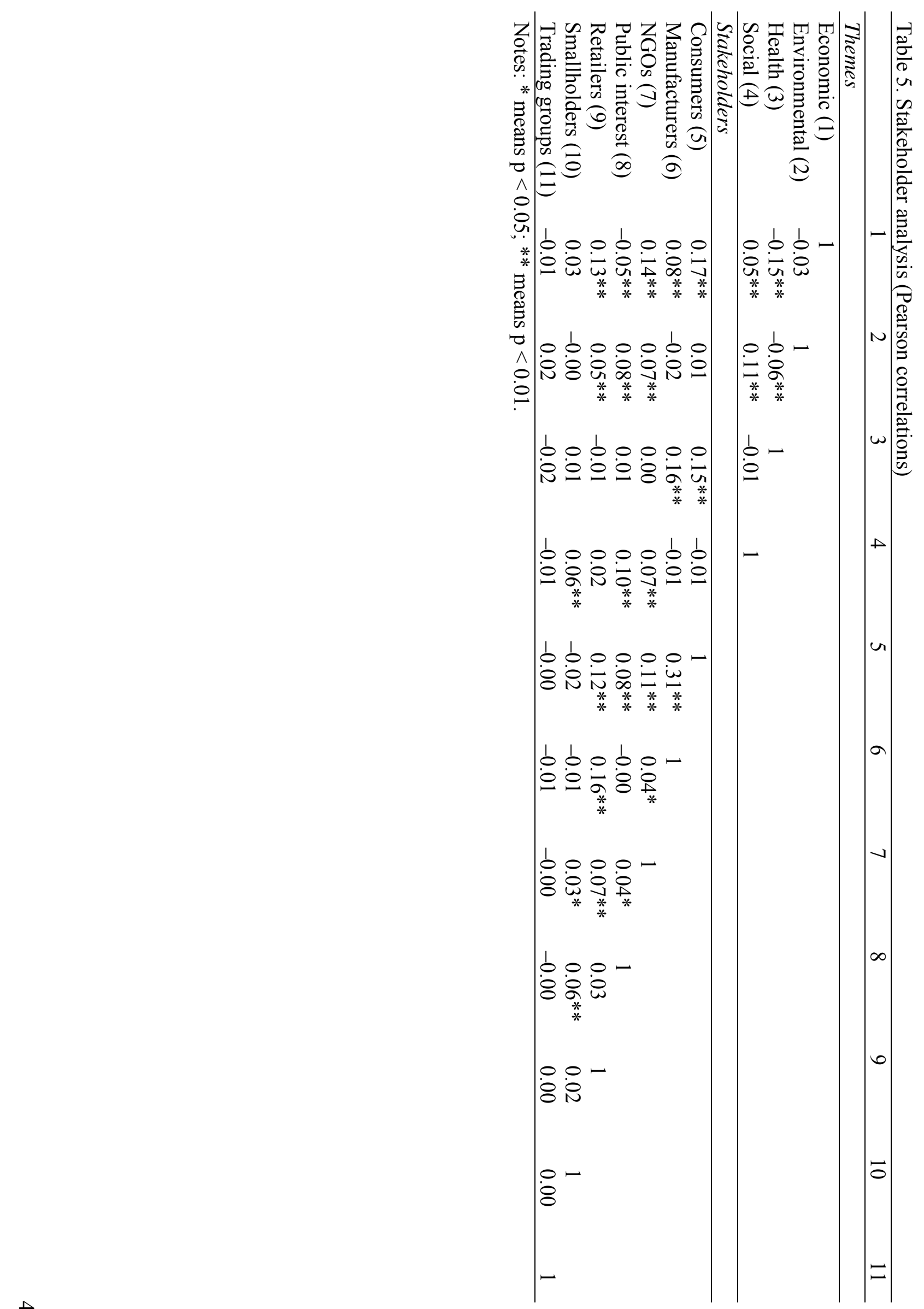


Figure 1. Shifts in themes over time
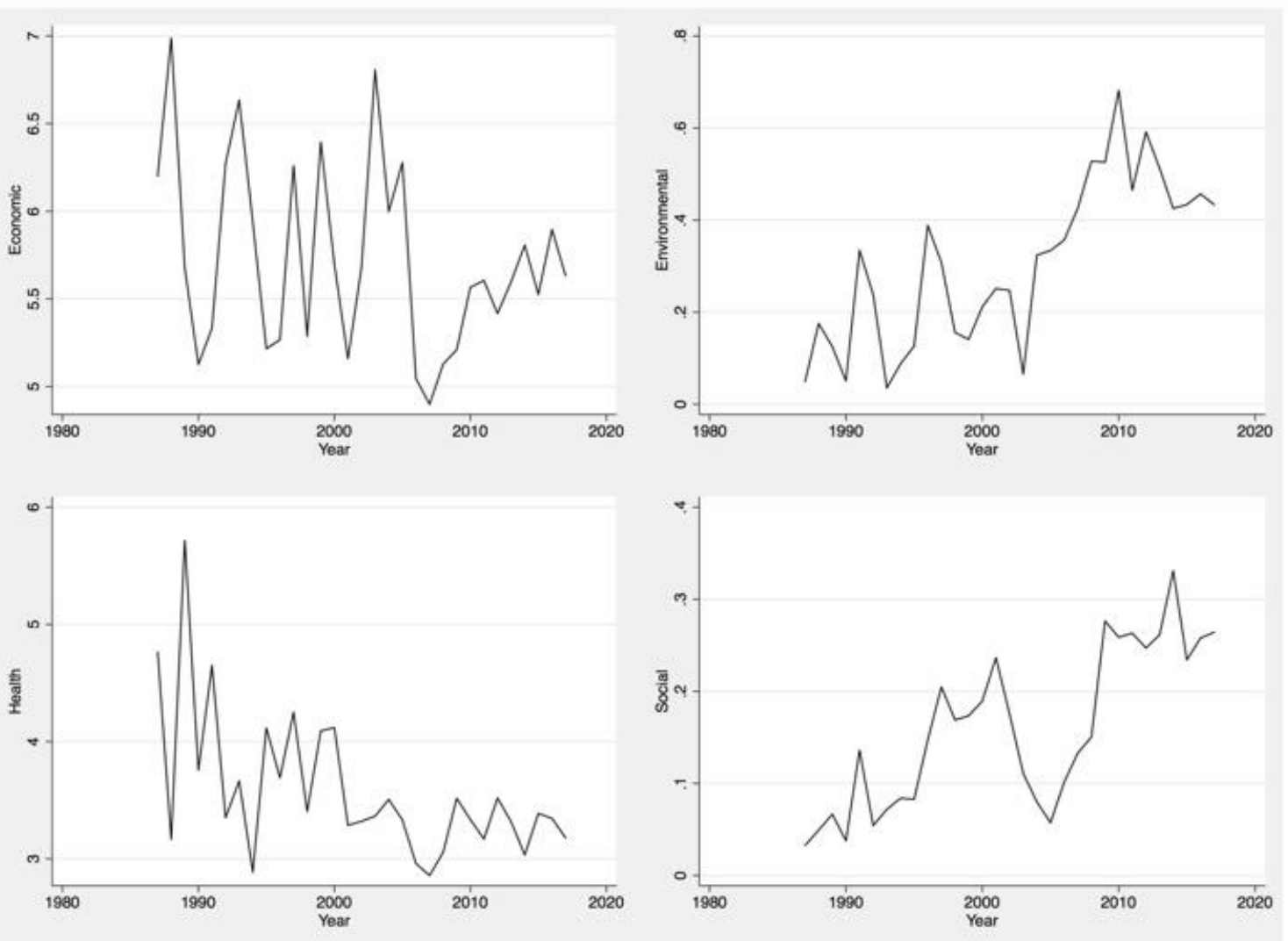

Notes: The lines represent the percentages of words by year. The period 1979-1986 is excluded in these figures because, in those years, we have less than 20 articles per year. 
Figure 2. Producing vs. Consuming Countries (t-tests)

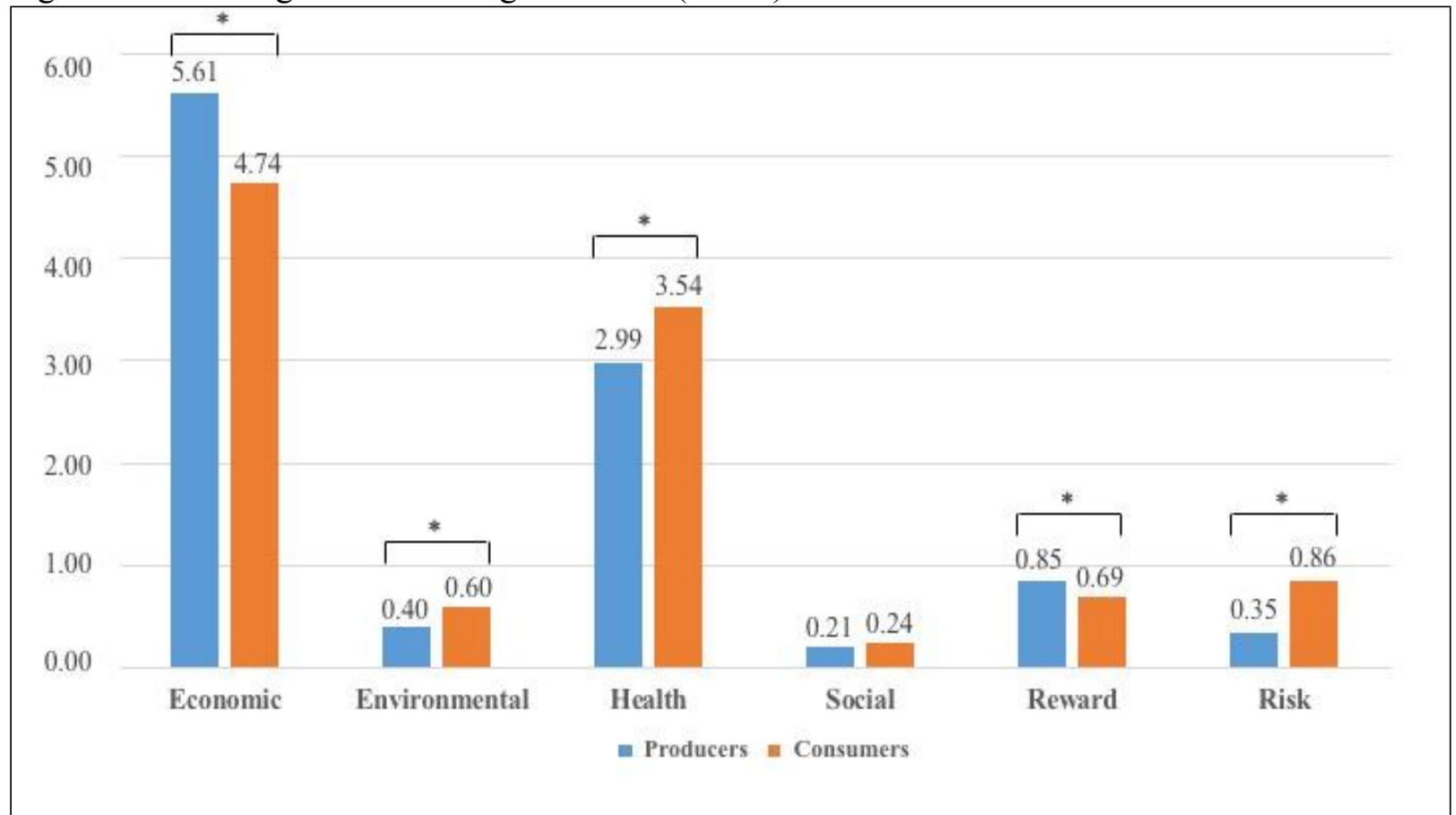

Notes: The histograms represent the percentages of words by producing vs. consuming countries.

The asterisk indicates that the difference between the two compared means is statistically significant $(\mathrm{p}<0.05)$. 


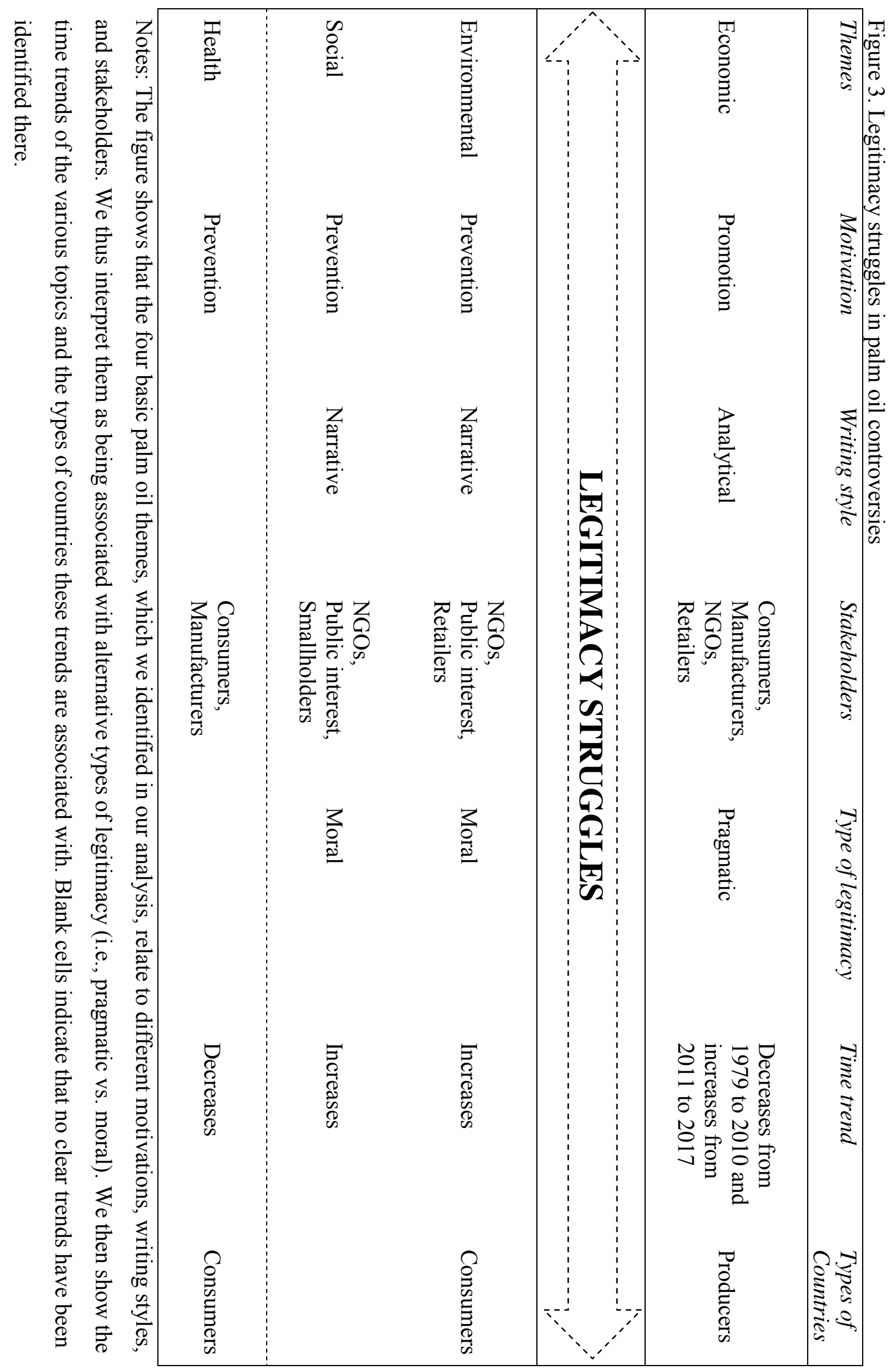



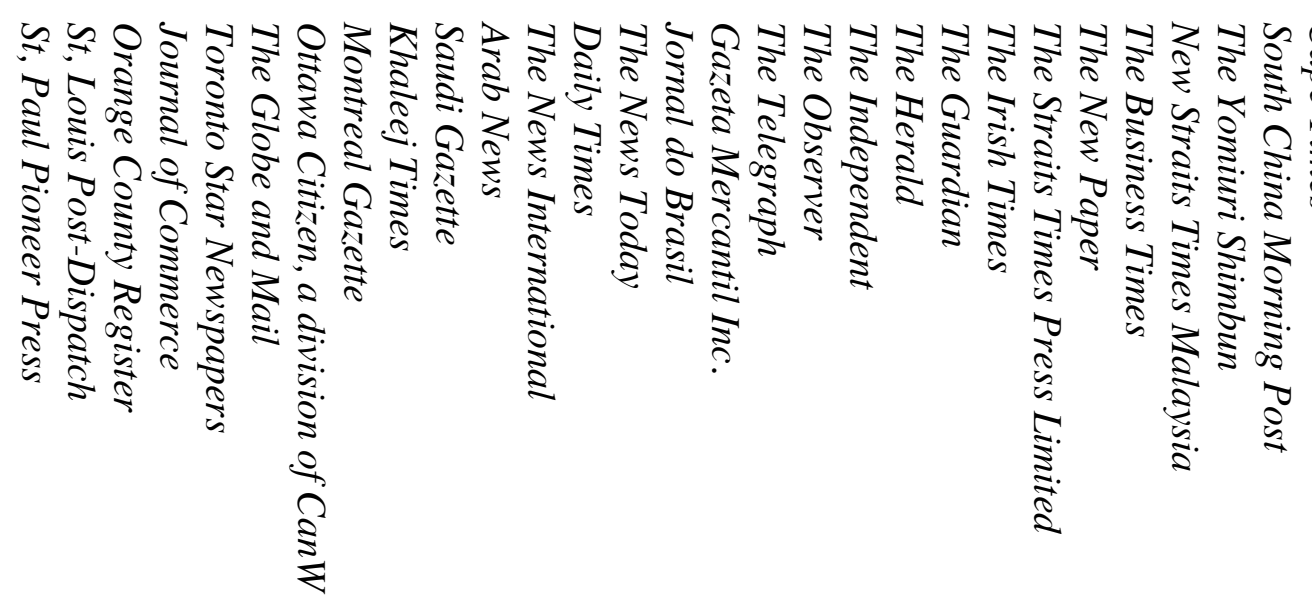

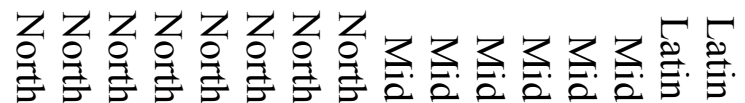

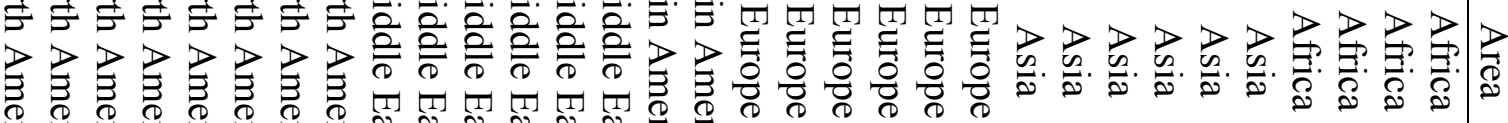

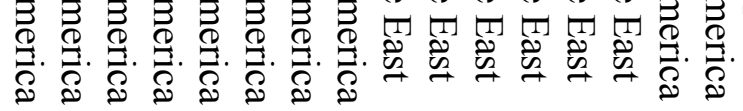

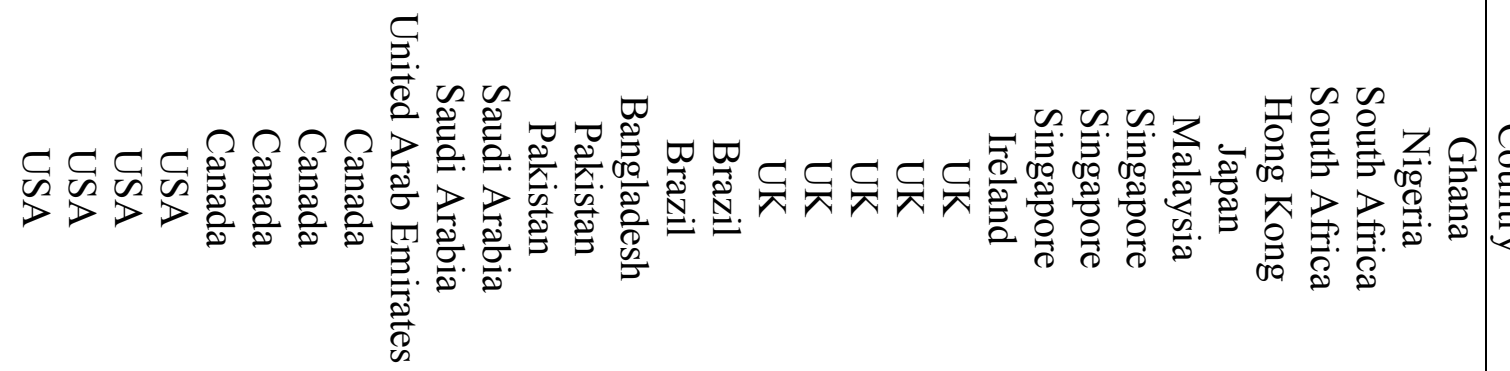

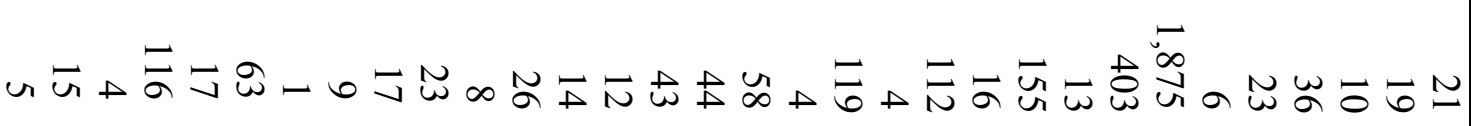

Nov

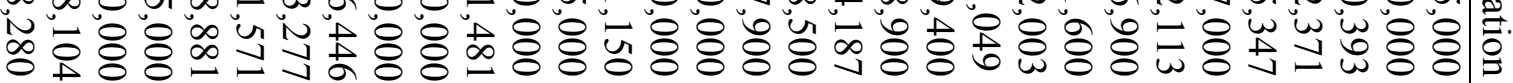

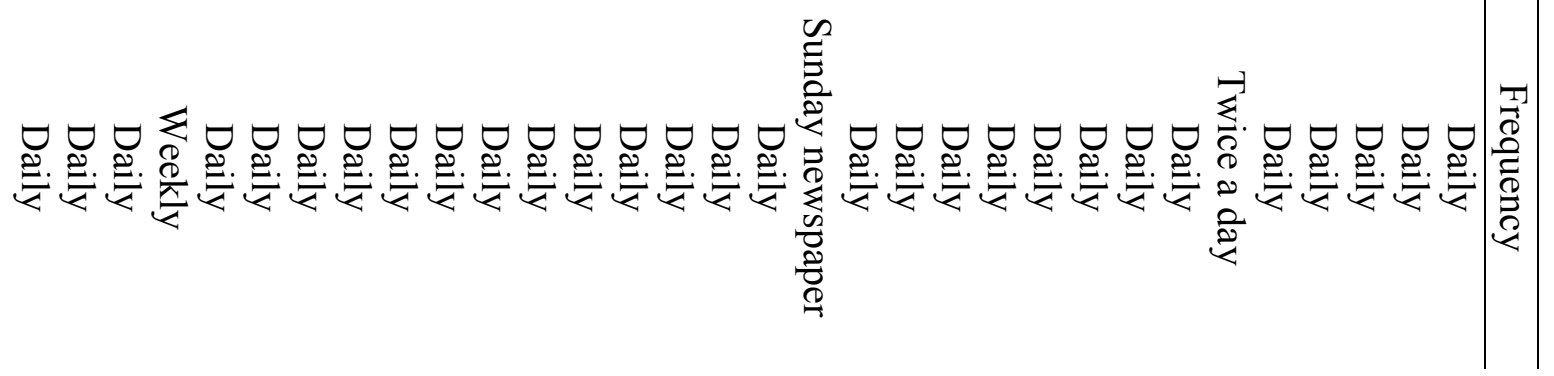




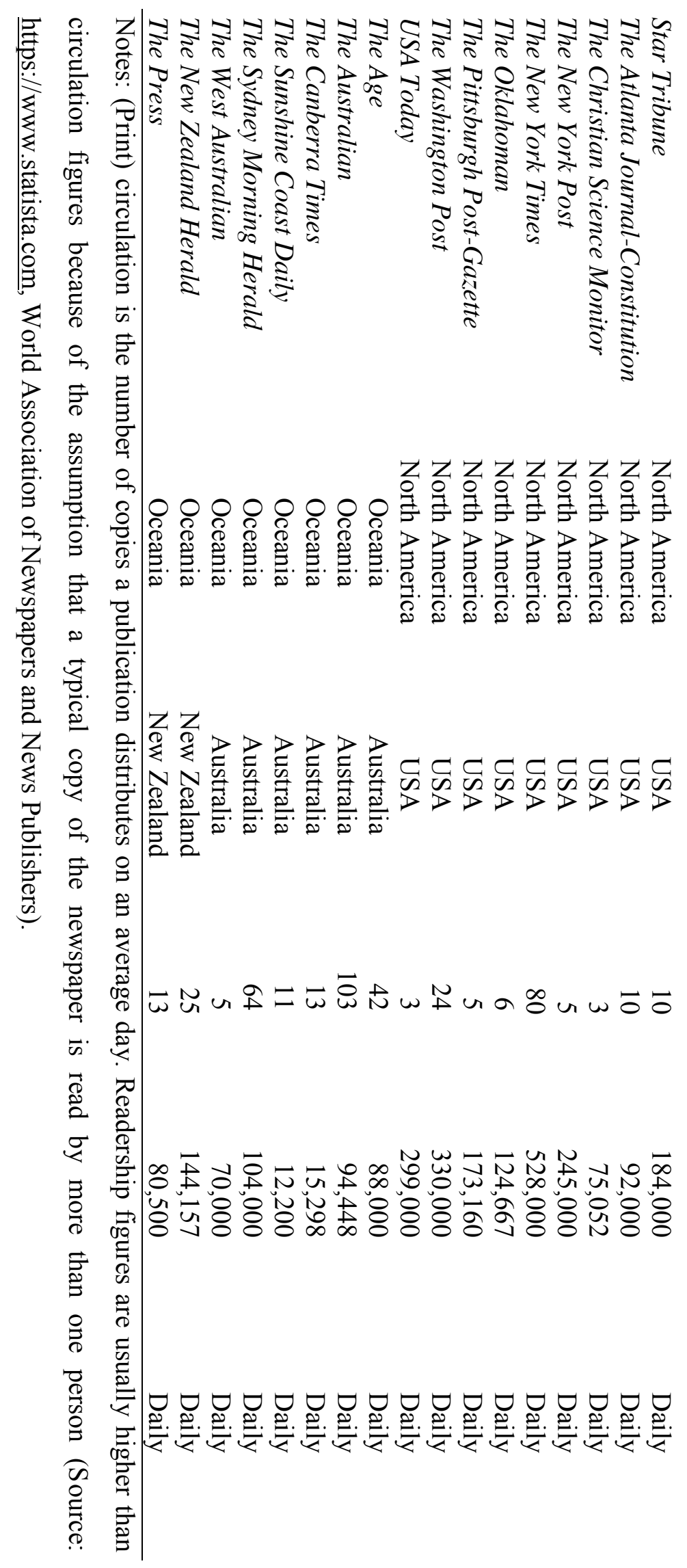


Appendix B. Descriptive statistics

\begin{tabular}{lrccr}
\hline & Mean & Std. Deviation & Minimum & Maximum \\
\hline Economic & 5.48 & 2.02 & 0.40 & 14.75 \\
Environmental & 0.43 & 0.62 & 0.00 & 4.54 \\
Health & 3.36 & 1.81 & 0.45 & 16.50 \\
Social & 0.20 & 0.20 & 0.00 & 2.16 \\
Reward & 0.84 & 0.59 & 0.00 & 3.90 \\
Risk & 0.44 & 0.43 & 0.00 & 2.85 \\
Analytical style & 95.01 & 3.85 & 56.04 & 99.00 \\
Narrative style & 4.84 & 1.43 & 0.28 & 11.19 \\
Consumers & 0.09 & 0.17 & 0.00 & 1.73 \\
Manufacturers & 0.03 & 0.11 & 0.00 & 1.73 \\
NGOs & 0.02 & 0.12 & 0.00 & 1.56 \\
Public interest & 0.08 & 0.16 & 0.00 & 1.71 \\
Retailers & 0.03 & 0.10 & 0.00 & 1.40 \\
Smallholders & 0.03 & 0.16 & 0.00 & 2.85 \\
Trading groups & 0.00 & 0.00 & 0.00 & 0.10 \\
\hline Notes: Mean & Num & $0 f i c t$
\end{tabular}

Notes: Mean $=($ Number of dictionary-related words $/$ Total words of the article $) \times$ 100. The "analytical style" variable is automatically re-scaled by LIWC to reflect a 100-point scale ranging from 0 to 100. 


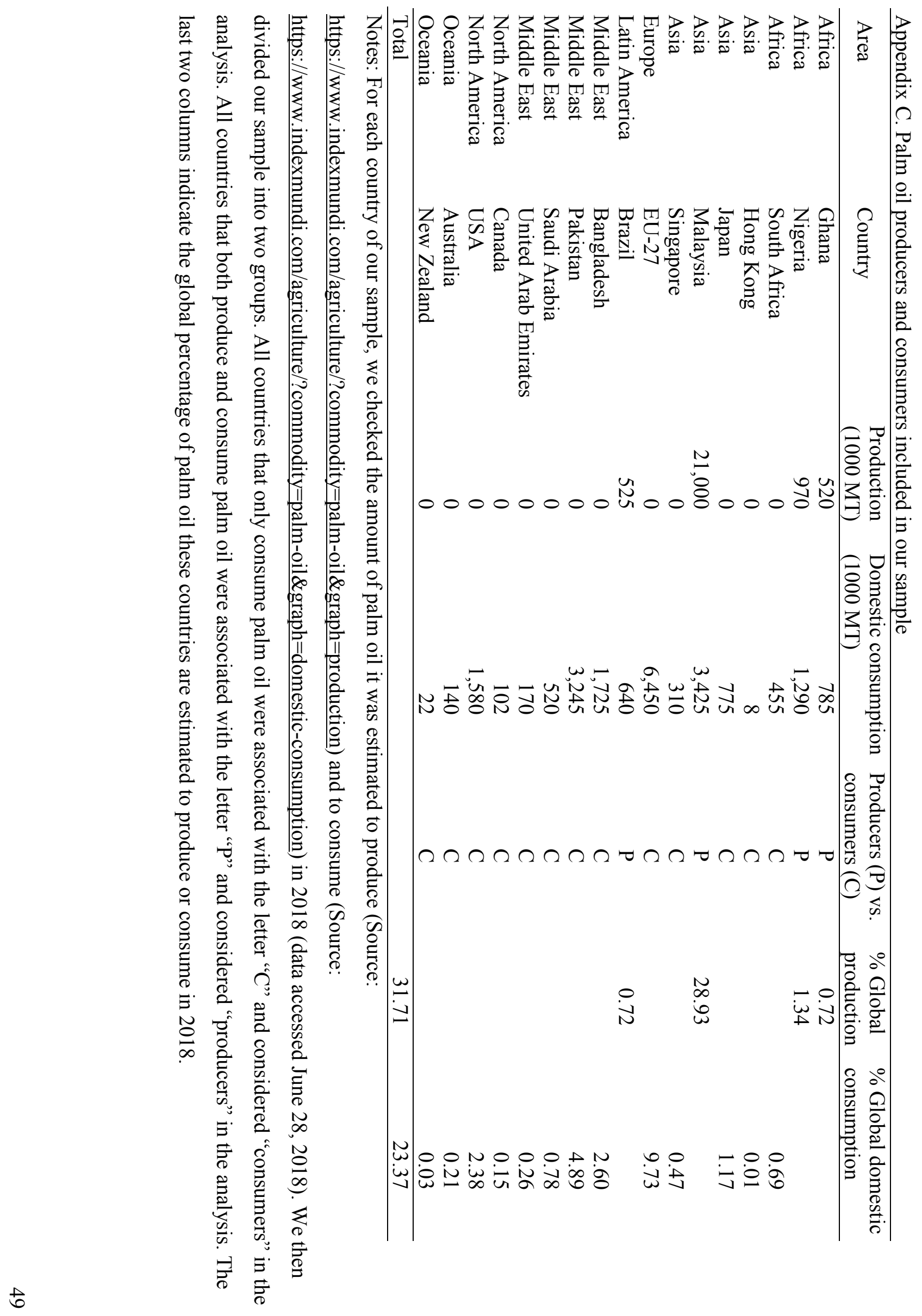

